\title{
Resolution and Fidelity of Oxygen Isotopes as Paleotemperature Proxies in Bivalve Mollusk Shells: Models and Observations
}

\author{
DAVID H. GOODWIN, BERND R. SCHÖNE,* and DAVID L. DETTMAN \\ Department of Geosciences, University of Arizona, Tucson, AZ, 85721, E-mail: dgoodwin@geo.arizona.edu
}

PALAIOS, 2003, V. 18, p. 110-125

Bivalve mollusks are biological chart recorders: their shells contain a record of environmental conditions in the form of geochemical variation. However, these records are often incomplete. Growth cessations and / or changing growth rates can reduce the range and resolution of the recorded environmental conditions.

To investigate the effects of these variables on geochemical profiles, stable oxygen isotope $\left(\delta^{18} \mathrm{O}\right)$ profiles were modeled using several growth parameters. Two sets of profiles were calculated: one with constant daily increment widths, the other based on the annual pattern of daily increment width variation observed in the northern Gulf of California bivalve mollusk Chione cortezi. In both sets of models, multiyear $\delta^{18} \mathrm{O}$ profiles were calculated assuming that the bivalve shell grows continuously throughout its life. Other profiles were calculated to simulate an ontogenetic decrease in growth rate by decreasing the growth period, daily growth rate, or both. Altering the growth period simulates the effects of thermal thresholds, above or below which no shell material is deposited. Decreasing the daily growth rate results in lower annual shell growth rates while keeping the growth period constant. Combining the two provides a more accurate representation of bivalve shell growth in many subtropical and temperate species.

In addition to the modeling exercise, the shell of a Chione cortezi that lived in the northern Gulf of California was sampled in two ways. First, low-resolution (300 micron) samples were recovered from the entire growth profile along the axis of maximum shell height (umbo to the commissure). Second, high-resolution (50 micron) samples were taken from regions of the shell representing winter growth from late in the bivalve's life.

Modeling results and observations indicate that the fullest range of environmental conditions only is reflected in the earliest years of growth; profiles from successive years have reduced amplitudes, sample resolutions, or both. Variation of intra-annual growth rate in models simulating continuous growth can produce cuspate $\delta^{18} O$ profiles that mimic shutdowns. More detailed sampling in later stages of ontogeny can reconstruct a fuller range of environmental conditions. Finally, within-shell trends in isotopic amplitudes and averages may reflect decreases in growth rate rather than environmental fluctuations. Therefore, particular care should be taken when interpreting inter-annual isotope profiles from long-lived species.

* Current address: Institute for Geology and Paleontology, Increments Group, Johann Wolfgang Goethe University, D-60054 Frankfurt, Germany

Copyright $\odot$ 2003, SEPM (Society for Sedimentary Geology)
INTRODUCTION

Accretionary hard parts are valuable sources of environmental information (Jones, 1983; Wefer and Berger, 1991). Bivalve mollusks in particular are an important source of geochemically archived environmental information. However, the growth of bivalves rarely is constant and growth cessations are common (e.g., Jones and Quitmyer, 1996). These growth halts prevent bivalves from archiving continuous and complete records of environmental conditions.

The rate and timing of bivalve shell growth is controlled by temperature (Pannella and MacClintock, 1969; Kennish and Olsson, 1975; Jones et al., 1978, 1989), salinity (Koike, 1980), age and reproductive cycle (Hall et al., 1974; Sato, 1995), tidal cycle and intertidal position (Berry and Barker, 1975; Lutz and Rhoads, 1980; Ohno, 1989), and nutrient availability (Coe, 1948). However, temperature appears to be the dominant factor controlling intra-annual growth rates (Goodwin et al., 2001; Schöne et al., 2002). Growth cessations occur when temperatures exceed the thermal tolerances of individual organisms (Jones and Quitmyer, 1996). Furthermore, when temperatures approach but do not exceed the thermal tolerances, growth rates and sub-annual growth increments are reduced (Goodwin et al., 2001). Thus, the proportion and resolution of recorded environmental conditions are affected by the duration of growth periods and/or changing growth rates.

Here the influence of growth-period duration and variation of growth rates on inter-annual geochemical profiles is investigated. Using a simple model of environmental conditions, two sets of stable oxygen isotope $\left(\delta^{18} \mathrm{O}\right)$ profiles were calculated, one with constant daily increment widths and the other based on the annual pattern of daily increment width variation, from the northern Gulf of California bivalve mollusk Chione cortezi. In each set of models, a series of profiles reflecting various intra- and inter-annual growth patterns was calculated. First, a profile in which the full range of environmental conditions was represented was calculated. This model was designed to simulate a $\delta^{18} \mathrm{O}$ profile from an organism that grows continuously throughout its ontogeny. Second, profiles were modeled with various ontogenetic declines in growth rate, which is a feature of many bivalve mollusks (e.g., Appleyard and Dealteris, 2001; also see King, 1995, for a general discussion). This decrease in growth rate was modeled in three ways: (1) the growth period (i.e., the number of days of shell deposition) was shortened through the bivalve's life; (2) the width of daily growth increments was decreased while keeping the growth period constant; and (3) both the growth period and daily increment widths were decreased through ontogeny.

These modeled $\delta^{18} \mathrm{O}$ profiles reveal how different styles 0883-1351/03/0018-0003/\$3.00 
of growth affect the range and resolution of geochemical archives. A strategy for partially correcting for the loss of environmental information through ontogeny also is investigated. Although the model profiles presented here illustrate the influence of various growth parameters on stable oxygen isotope profiles, these findings can be applied to other geochemical systems. It would be a simple matter of substituting a different isotopic or minor-element system, in place of oxygen isotopes, in order to investigate the effects of various growth parameters on different geochemical profiles.

\section{METHODS}

Two sets of hypothetical, multi-year, stable oxygen isotope profiles were calculated using a simple temperature model, several different growth periods, and two intra-annual growth models. Modeled profiles are six years long and consist of $\delta^{18} \mathrm{O}$ values representing continuous sampling from the umbo to the commissure along the axis of maximum shell height.

The temperature model is based on annual temperature variation observed in the Colorado River delta region (Hastings, 1964; Goodwin et al., 2001). Each day of the year is assigned a temperature according to the following equation:

$$
\mathrm{Y}=(10 \cos (0.01721 \mathrm{X}+\Pi))+20,
$$

where $\mathrm{Y}$ is the average daily temperature $\left({ }^{\circ} \mathrm{C}\right)$ and $\mathrm{X}$ is the day of the year (1-365). The annual temperature range is $20^{\circ} \mathrm{C}$, similar to values reported for the northern Gulf of California (Hastings, 1964; Goodwin et al., 2001). The coldest temperature $\left(10^{\circ} \mathrm{C}\right)$ occurs on January 1 and again on December 31 (days 1 and 365, respectively), and the warmest average daily temperature $\left(30^{\circ} \mathrm{C}\right)$ occurs on July 1 and 2 (days 182 and 183, respectively).

The growth period is the interval during which shell material is added at the shell margin. A full year of growth is represented by 365 days of growth; however, in many bivalves, fewer daily increments are observed in later years of life. Therefore, most of the modeled profiles have growth periods less than a full year. Only the full-year models represent 12 months (365 days) of growth (Tables 1 and 2). The constant-winter-shutdown models and the constantsummer-shutdown models represent ten months of growth in each calendar year (constant-winter-shutdown: no growth in December and January; constant-summershutdown: no growth in June and July). The lengtheningwinter-shutdown models and the lengthening-summershutdown models have growth periods that become progressively shorter through the ontogeny of the hypothetical bivalve (Table 1 and 2). The first year of each of these models is a full year, and the growth interval is shortened by two months in each of the following years. The lengthening-winter-and-summer-shutdown models have a growth period that is truncated in both the winter and summer. These growth periods were chosen to illustrate a wide variety of growth conditions, some or all of which might be found in nature.

In addition to various growth periods, both sets of modeled $\delta^{18} \mathrm{O}$ profiles are based on one of two daily growth rate (increment width) models. The first set of profiles is based on constant daily increment widths: each day of the year has the same daily increment width. The second set of $\delta^{18} \mathrm{O}$ profiles uses an idealized daily increment width profile based on the growth of the northern Gulf of California bivalve mollusk Chione cortezi (Fig. 1; for detailed discussion see Goodwin et al., 2001). This simplified profile preserves the general trends seen in daily increment widths of $C$. cortezi, while removing higher frequency variation that probably is related to the tidal cycle (Goodwin et al., 2001).

Several of the $\delta^{18} \mathrm{O}$ profiles also incorporate a reduction in daily increment widths through the bivalve's life. This phenomenon has been observed in the daily increment width profiles from many species in the northern Gulf of California. Therefore, inclusion of this variable in the modeled $\delta^{18} \mathrm{O}$ profiles is reasonable. In models that incorporate a reduction in daily increment widths, the increment width of a given day is reduced by $50 \%$ with respect to the corresponding day in the previous year, regardless of the intra-annual growth rate model. For example, if the increment width on January 1 from the bivalve's first year of life is 100 microns, then the width of January 1 in the second year is 50 microns. In this way, the linear growth of successive years in models with reduced increment widths is reduced by at least $50 \%$ (Tables 1 and 2).

All $\delta^{18} \mathrm{O}$ values were calculated using Grossman and Ku's (1986) empirically determined temperature relationship for biogenic aragonite. Their original equation was modified because they reported water values as SMOW minus $0.2 \%$. The rewritten equation is:

$$
\begin{aligned}
& \text { temperature } \\
& \quad=20.6-4.34\left[\delta^{18} \mathrm{O}_{\text {aragonite }}-\left(\delta^{18} \mathrm{O}_{\text {water }}-0.2\right)\right] .
\end{aligned}
$$

All temperatures are reported in degrees Celsius. Each $4.34^{\circ} \mathrm{C}$ change in temperature results in a one-permil shift in shell carbonate. Algebraically solving for $\delta^{18} \mathrm{O}$ of the shell results in the following equation, which was used to calculate all $\delta^{18} \mathrm{O}$ values in all of the modeled profiles:

$$
\begin{aligned}
& \delta^{18} \mathrm{O}_{\text {aragonite }} \\
&= {\left[(\text { temperature }-20.6)-\left(4.34 \times\left(\delta^{18} \mathrm{O}_{\text {water }}-0.2\right)\right)\right] } \\
& /-4.34 .
\end{aligned}
$$

In order to interpret modeled profiles more easily, and because the annual water $\delta^{18} \mathrm{O}$ variability in the northern Gulf of California is small ( $\sim 0.5 \%$; David Dettman, unpublished data), the isotopic composition of the water in which these hypothetical bivalves grew is assumed a constant $0 \%$.

All of the modeled $\delta^{18} \mathrm{O}$ profiles are calculated in the following manner: $\delta^{18} \mathrm{O}$ profiles begin at the umbo and progress to the commissure along the axis of maximum shell height. Individual samples are calculated assuming a drill-bit diameter of 300 microns. The first sample in each modeled profile incorporates the first increment at the umbo. The widths of the following daily increments $\left(2^{\text {nd }}\right.$, $3^{\text {rd }}, 4^{\text {th }}$, etc.) are added until their combined width is equal to or greater than 300 microns, at which point the summing procedure is halted and the weighted average of the daily $\delta^{18} \mathrm{O}$ values in the sample is calculated. The next sample begins with the increment following the last one used in the previous sample. This procedure was followed for the entire shell. In this way, all daily increments are incorporated in one and only one $\delta^{18} \mathrm{O}$ sample in the modeled profile. Only those increments between the final full 300-micron sample and the commissure are not included 
TABLE 1-Data from modeled $\delta^{18} \mathrm{O}$ profiles with constant increment widths. Growth period: part(s) of the year during which shell accretion occurred; Inc. width: increment width of each daily growth increment in each year; \# Days: number of daily growth increments in each year; \# Samples: number of samples in each year; Max. $\delta^{18} \mathrm{O}$ : maximum $\delta^{18} \mathrm{O}$ value in each year; Min. $\delta^{18} \mathrm{O}$ : minimum $\delta^{18} \mathrm{O}$ value in each year; Avg. $\delta^{18} \mathrm{O}$ : weighted annual $\delta^{18} \mathrm{O}$ average; Amp. $\delta^{18} \mathrm{O}$ : annual $\delta^{18} \mathrm{O}$ amplitude (based on maximum and minimum $\delta^{18} \mathrm{O}$ values); Annual growth: cumulative growth of each year; \% First year growth: annual growth expressed as a percent of the first year's growth; \% First year amplitude: isotopic amplitude expressed as a percent of the first year's amplitude.

\begin{tabular}{|c|c|c|c|c|c|c|c|c|c|c|c|}
\hline $\begin{array}{c}\text { Year } \\
\#\end{array}$ & Growth period & $\begin{array}{l}\text { Inc. width } \\
\text { (microns) }\end{array}$ & \# Days & $\begin{array}{l}\text { \# Sam- } \\
\text { ples }\end{array}$ & $\begin{array}{l}\text { Max. } \\
\delta^{18} \mathrm{O}\end{array}$ & $\begin{array}{l}\text { Min. } \\
\delta^{18} \mathrm{O}\end{array}$ & $\begin{array}{l}\text { Avg. } \\
\delta^{18} \mathrm{O}\end{array}$ & $\begin{array}{c}\text { Amp. } \\
\delta^{18} \mathrm{O}\end{array}$ & $\begin{array}{c}\text { Annual } \\
\text { growth } \\
(\mathrm{cm})\end{array}$ & $\begin{array}{l}\text { \% First } \\
\text { year } \\
\text { growth }\end{array}$ & $\begin{array}{c}\% \text { First } \\
\text { year } \\
\text { amplitude }\end{array}$ \\
\hline \multicolumn{12}{|c|}{ Full Year } \\
\hline 1 & Full Year & 100 & 365 & 121 & 2.24 & -2.37 & -0.06 & 4.61 & 3.65 & 100 & 100 \\
\hline 2 & Full Year & 100 & 365 & 121 & 2.24 & -2.37 & -0.06 & 4.61 & 3.65 & 100 & 100 \\
\hline 3 & Full Year & 100 & 365 & 121 & 2.24 & -2.37 & -0.06 & 4.61 & 3.65 & 100 & 100 \\
\hline 4 & Full Year & 100 & 365 & 121 & 2.24 & -2.37 & -0.06 & 4.61 & 3.65 & 100 & 100 \\
\hline 5 & Full Year & 100 & 365 & 121 & 2.24 & -2.37 & -0.06 & 4.61 & 3.65 & 100 & 100 \\
\hline 6 & Full Year & 100 & 365 & 121 & 2.24 & -2.37 & -0.06 & 4.61 & 3.65 & 100 & 100 \\
\hline \multicolumn{12}{|c|}{ Constant Winter Shutdown } \\
\hline 1 & Feb-Nov & 100 & 303 & 101 & 1.90 & -2.37 & -0.51 & 4.27 & 3.03 & 100 & 100 \\
\hline 2 & Feb-Nov & 100 & 303 & 101 & 1.90 & -2.37 & -0.51 & 4.27 & 3.03 & 100 & 100 \\
\hline 3 & Feb-Nov & 100 & 303 & 101 & 1.90 & -2.37 & -0.51 & 4.27 & 3.03 & 100 & 100 \\
\hline 4 & Feb-Nov & 100 & 303 & 101 & 1.90 & -2.37 & -0.51 & 4.27 & 3.03 & 100 & 100 \\
\hline 5 & Feb-Nov & 100 & 303 & 101 & 1.90 & -2.37 & -0.51 & 4.27 & 3.03 & 100 & 100 \\
\hline 6 & Feb-Nov & 100 & 303 & 101 & 1.90 & -2.37 & -0.51 & 4.27 & 3.03 & 100 & 100 \\
\hline \multicolumn{12}{|c|}{ Lengthening Winter Shutdown } \\
\hline 1 & Full Year & 100 & 365 & 121 & 2.24 & -2.37 & -0.06 & 4.61 & 3.65 & 100 & 100 \\
\hline 2 & Jan-Nov & 100 & 334 & 112 & 2.24 & -2.37 & -0.27 & 4.61 & 3.34 & 91.51 & 100 \\
\hline 3 & Feb-Oct & 100 & 273 & 90 & 1.86 & -2.37 & -0.75 & 4.23 & 2.73 & 74.79 & 91.76 \\
\hline 4 & Mar-Sept & 100 & 214 & 72 & 1.08 & -2.37 & -1.22 & 3.45 & 2.14 & 58.63 & 74.84 \\
\hline 5 & Apr-Aug & 100 & 153 & 51 & -0.09 & -2.37 & -1.70 & 2.28 & 1.53 & 41.92 & 49.46 \\
\hline 6 & May-Jul & 100 & 92 & 30 & -1.22 & -2.37 & -2.05 & 1.15 & 0.92 & 25.21 & 24.95 \\
\hline \multicolumn{12}{|c|}{ Constant Summer Shutdown } \\
\hline 1 & Jan-May: Aug-Dec & 100 & 304 & 101 & 2.24 & -2.04 & 0.38 & 4.28 & 3.04 & 100 & 100 \\
\hline 2 & Jan-May: Aug-Dec & 100 & 304 & 101 & 2.24 & -2.04 & 0.38 & 4.28 & 3.04 & 100 & 100 \\
\hline 3 & Jan-May: Aug-Dec & 100 & 304 & 102 & 2.24 & -2.04 & 0.38 & 4.28 & 3.04 & 100 & 100 \\
\hline 4 & Jan-May: Aug-Dec & 100 & 304 & 101 & 2.24 & -2.04 & 0.38 & 4.28 & 3.04 & 100 & 100 \\
\hline 5 & Jan-May: Aug-Dec & 100 & 304 & 101 & 2.24 & -2.04 & 0.38 & 4.28 & 3.04 & 100 & 100 \\
\hline 6 & Jan-May: Aug-Dec & 100 & 304 & 102 & 2.24 & -2.04 & 0.38 & 4.28 & 3.04 & 100 & 100 \\
\hline \multicolumn{12}{|c|}{ Lengthening Summer Shutdown } \\
\hline 1 & Full Year & 100 & 365 & 121 & 2.24 & -2.37 & -0.06 & 4.61 & 3.65 & 100 & 100 \\
\hline 2 & Jan-May: Aug-Dec & 100 & 304 & 102 & 2.24 & -2.04 & 0.38 & 4.28 & 3.04 & 83.29 & 92.84 \\
\hline 3 & Jan-Apr: Sept-Dec & 100 & 242 & 80 & 2.24 & -1.16 & 0.90 & 3.40 & 2.42 & 66.30 & 73.75 \\
\hline 4 & Jan-Mar: Oct-Dec & 100 & 182 & 61 & 2.24 & -0.01 & 1.41 & 2.26 & 1.82 & 49.86 & 49.02 \\
\hline 5 & Jan-Feb: Nov-Dec & 100 & 120 & 40 & 2.24 & 1.15 & 1.85 & 1.09 & 1.20 & 32.88 & 23.64 \\
\hline 6 & Jan: Dec & 100 & 62 & 21 & 2.24 & 1.93 & 2.13 & 0.31 & 0.62 & 16.99 & 6.72 \\
\hline \multicolumn{12}{|c|}{ Reduced Increment Width } \\
\hline 1 & Full Year & 100 & 365 & 121 & 2.24 & -2.37 & -0.06 & 4.61 & 3.65 & 100 & 100 \\
\hline 2 & Full Year & 50 & 365 & 61 & 2.24 & -2.36 & -0.06 & 4.60 & 1.83 & 50.00 & 99.78 \\
\hline 3 & Full Year & 25 & 365 & 30 & 2.24 & -2.36 & -0.06 & 4.60 & 0.91 & 25.00 & 99.78 \\
\hline 4 & Full Year & 12.5 & 365 & 16 & 2.23 & -2.35 & -0.06 & 4.58 & 0.46 & 12.50 & 99.35 \\
\hline 5 & Full Year & 6.25 & 365 & 7 & 2.05 & -2.17 & -0.06 & 4.22 & 0.23 & 6.25 & 91.54 \\
\hline 6 & Full Year & 3.125 & 365 & 4 & 2.13 & -2.07 & -0.06 & 4.20 & 0.11 & 3.13 & 91.11 \\
\hline \multicolumn{12}{|c|}{ Lengthening Winter Shutdown w/RIW } \\
\hline 1 & Full Year & 100 & 365 & 121 & 2.24 & -2.37 & -0.06 & 4.61 & 3.65 & 100 & 100 \\
\hline 2 & Jan-Nov & 50 & 334 & 56 & 2.24 & -2.36 & -0.27 & 4.60 & 1.67 & 45.75 & 99.78 \\
\hline 3 & Feb-Oct & 25 & 273 & 23 & 1.84 & -2.35 & -0.74 & 4.19 & 0.68 & 18.70 & 90.89 \\
\hline 4 & Mar-Sept & 12.5 & 214 & 9 & 0.75 & -2.33 & -1.22 & 3.08 & 0.27 & 7.33 & 66.81 \\
\hline 5 & Apr-Aug & 6.25 & 153 & 3 & -0.93 & -2.17 & -1.70 & 1.24 & 0.10 & 2.62 & 26.90 \\
\hline 6 & May-Jul & 3.125 & 92 & 1 & -1.96 & -1.96 & -2.05 & - & 0.03 & 0.79 & - \\
\hline \multicolumn{12}{|c|}{ Lengthening Summer Shutdown w/RIW } \\
\hline 1 & Full Year & 100 & 365 & 121 & 2.24 & -2.37 & -0.06 & 4.61 & 3.65 & 100 & 100 \\
\hline 2 & Jan-May: Aug-Dec & 50 & 304 & 51 & 2.24 & -2.00 & 0.38 & 4.24 & 1.52 & 41.64 & 91.97 \\
\hline 3 & Jan-Apr: Sept-Dec & 25 & 242 & 20 & 2.24 & -1.08 & 0.90 & 3.32 & 0.61 & 16.58 & 72.02 \\
\hline 4 & Jan-Mar: Oct-Dec & 12.5 & 182 & 8 & 2.23 & 0.23 & 1.41 & 2.00 & 0.23 & 6.23 & 43.38 \\
\hline 5 & Jan-Feb: Nov-Dec & 6.25 & 120 & 2 & 2.03 & 1.52 & 1.85 & 0.51 & 0.08 & 2.05 & 11.06 \\
\hline 6 & Jan: Dec & 3.125 & 62 & 1 & 2.13 & 2.13 & 2.13 & - & 0.02 & 0.53 & - \\
\hline \multicolumn{12}{|c|}{ Lengthening Summer and Winter Shutdown w/RIW } \\
\hline 1 & Full Year & 100 & 365 & 121 & 2.24 & -2.37 & -0.06 & 4.61 & 3.65 & 100 & 100 \\
\hline 2 & Jan-May: Aug-Nov & 50 & 273 & 46 & 2.24 & -2.00 & 0.18 & 4.24 & 1.37 & 37.53 & 91.97 \\
\hline 3 & Feb-Apr: Sept-Oct & 25 & 150 & 12 & 1.82 & -1.08 & 0.26 & 2.90 & 0.38 & 10.41 & 62.91 \\
\hline 4 & Mar & 12.5 & 31 & 1 & 0.97 & 0.97 & 0.57 & - & 0.04 & 1.10 & - \\
\hline
\end{tabular}


TABLE 2-Data from modeled $\delta^{18} \mathrm{O}$ profiles based on $C$. cortezi-increment-width model. Growth period: part(s) of the year during which shell accretion occurred; Inc. width: increment width of each daily increment in each year; \# Days: number of daily increments in each year; \# Samples: number of samples in each year: Max. $\delta^{18} \mathrm{O}$ : maximum $\delta^{18} \mathrm{O}$ value in each year; Min. $\delta^{18} \mathrm{O}$ : minimum $\delta^{18} \mathrm{O}$ value in each year; Avg. $\delta^{18} \mathrm{O}$ : weighted yearly average of daily increments in each year; Amp. $\delta^{18} \mathrm{O}$ : annual $\delta^{18} \mathrm{O}$ amplitude (based on maximum and minimum $\delta^{18} \mathrm{O}$ values); Annual growth: cumulative growth of each year; \% First year growth: annual growth expressed as a percent of the first year's growth; $\%$ First year amplitude: isotopic amplitude expressed as a percent of the first year's amplitude.

\begin{tabular}{|c|c|c|c|c|c|c|c|c|c|c|c|}
\hline $\begin{array}{c}\text { Year } \\
\#\end{array}$ & Growth period & $\begin{array}{l}\text { Inc. width } \\
\text { (microns) }\end{array}$ & \# Days & $\begin{array}{l}\text { \# Sam- } \\
\text { ples }\end{array}$ & $\begin{array}{l}\text { Max. } \\
\delta^{18} \mathrm{O}\end{array}$ & $\begin{array}{l}\text { Min. } \\
\delta^{18} \mathrm{O}\end{array}$ & $\begin{array}{l}\text { Avg. } \\
\delta^{18} \mathrm{O}\end{array}$ & $\begin{array}{l}\text { Amp. } \\
\delta^{18} \mathrm{O}\end{array}$ & $\begin{array}{l}\text { Annual } \\
\text { growth } \\
\text { (cm) }\end{array}$ & $\begin{array}{l}\% \text { First } \\
\text { year } \\
\text { growth }\end{array}$ & $\begin{array}{c}\% \text { First } \\
\text { year } \\
\text { amplitude }\end{array}$ \\
\hline \multicolumn{12}{|c|}{ Full Year } \\
\hline 1 & Full Year & variable & 365 & 116 & 2.09 & -2.37 & -1.03 & 4.46 & 4.42 & 100 & 100 \\
\hline 2 & Full Year & variable & 365 & 117 & 2.15 & -2.37 & -1.03 & 4.52 & 4.42 & 100 & 101.35 \\
\hline 3 & Full Year & variable & 365 & 117 & 2.15 & -2.37 & -1.03 & 4.52 & 4.42 & 100 & 101.35 \\
\hline 4 & Full Year & variable & 365 & 117 & 2.15 & -2.37 & -1.03 & 4.52 & 4.42 & 100 & 101.35 \\
\hline 5 & Full Year & variable & 365 & 117 & 2.15 & -2.37 & -1.03 & 4.52 & 4.42 & 100 & 101.35 \\
\hline 6 & Full Year & variable & 365 & 117 & 2.15 & -2.37 & -1.03 & 4.52 & 4.42 & 100 & 101.35 \\
\hline \multicolumn{12}{|c|}{ Constant Winter Shutdown } \\
\hline 1 & Feb-Nov & variable & 303 & 114 & 1.77 & -2.37 & -1.08 & 4.14 & 4.35 & 100 & 100 \\
\hline 2 & Feb-Nov & variable & 303 & 115 & 1.83 & -2.37 & -1.08 & 4.20 & 4.35 & 100 & 101.45 \\
\hline 3 & Feb-Nov & variable & 303 & 115 & 1.83 & -2.37 & -1.08 & 4.20 & 4.35 & 100 & 101.45 \\
\hline 4 & Feb-Nov & variable & 303 & 115 & 1.83 & -2.37 & -1.08 & 4.20 & 4.35 & 100 & 101.45 \\
\hline 5 & Feb-Nov & variable & 303 & 115 & 1.83 & -2.37 & -1.08 & 4.20 & 4.35 & 100 & 101.45 \\
\hline 6 & Feb-Nov & variable & 303 & 115 & 1.83 & -2.37 & -1.08 & 4.20 & 4.35 & 100 & 101.45 \\
\hline \multicolumn{12}{|c|}{ Lengthening Winter Shutdown } \\
\hline 1 & Full Year & variable & 365 & 116 & 2.09 & -2.37 & -1.03 & 4.46 & 4.42 & 100 & 100 \\
\hline 2 & Jan-Nov & variable & 334 & 116 & 2.15 & -2.37 & -1.05 & 4.52 & 4.39 & 99.32 & 101.35 \\
\hline 3 & Feb-Oct & variable & 237 & 113 & 1.83 & -2.37 & -1.13 & 4.20 & 4.27 & 96.61 & 94.17 \\
\hline 4 & Mar-Sept & variable & 214 & 103 & 1.02 & -2.37 & -1.26 & 3.39 & 3.98 & 90.05 & 76.01 \\
\hline 5 & Apr-Aug & variable & 153 & 84 & -0.07 & -2.37 & -1.56 & 2.30 & 3.27 & 73.98 & 51.57 \\
\hline 6 & May-Jul & variable & 92 & 52 & -1.21 & -2.37 & -1.98 & 1.16 & 2.13 & 48.19 & 26.01 \\
\hline \multicolumn{12}{|c|}{ Constant Summer Shutdown } \\
\hline 1 & Jan-May: Aug-Dec & variable & 304 & 92 & 2.09 & -2.03 & -0.58 & 4.12 & 3.24 & 100 & 100 \\
\hline 2 & Jan-May: Aug-Dec & variable & 304 & 93 & 2.15 & -2.03 & -0.58 & 4.18 & 3.24 & 100 & 101.46 \\
\hline$\overline{3}$ & Jan-May: Aug-Dec & variable & 304 & 93 & 2.15 & -2.03 & -0.58 & 4.18 & 3.24 & 100 & 101.46 \\
\hline 4 & Jan-May: Aug-Dec & variable & 304 & 93 & 2.15 & -2.03 & -0.58 & 4.18 & 3.24 & 100 & 101.46 \\
\hline 5 & Jan-May: Aug-Dec & variable & 304 & 93 & 2.15 & -2.03 & -0.58 & 4.18 & 3.24 & 100 & 101.46 \\
\hline 6 & Jan-May: Aug-Dec & variable & 304 & 93 & 2.15 & -2.03 & -0.58 & 4.18 & 3.24 & 100 & 101.46 \\
\hline \multicolumn{12}{|c|}{ Lengthening Summer Shutdown } \\
\hline 1 & Full Year & variable & 365 & 116 & 2.09 & -2.37 & -1.03 & 4.46 & 4.42 & 100 & 100 \\
\hline 2 & Jan-May: Aug-Dec & variable & 304 & 93 & 2.15 & -2.03 & -0.58 & 4.18 & 3.24 & 73.30 & 93.72 \\
\hline 3 & Jan-Apr: Sept-Dec & variable & 242 & 61 & 2.15 & -1.15 & -0.04 & 3.30 & 2.14 & 48.42 & 73.99 \\
\hline 4 & Jan-Mar: Oct-Dec & variable & 182 & 25 & 2.12 & -0.02 & 0.73 & 2.14 & 0.92 & 20.81 & 47.98 \\
\hline 5 & Jan-Feb: Nov-Dec & variable & 120 & 8 & 2.16 & 1.19 & 1.67 & 0.97 & 0.23 & 5.20 & 21.75 \\
\hline 6 & Jan: Dec & variable & 62 & 2 & 2.12 & 2.04 & 2.08 & 0.08 & 0.06 & 1.36 & 1.79 \\
\hline \multicolumn{12}{|c|}{ Reduced Increment Width } \\
\hline 1 & Full Year & variable & 365 & 116 & 2.09 & -2.37 & -1.03 & 4.46 & 4.42 & 100 & 100 \\
\hline 2 & Full Year & variable & 365 & 64 & 2.14 & -2.37 & -1.03 & 4.51 & 2.21 & 50.00 & 101.12 \\
\hline 3 & Full Year & variable & 365 & 34 & 2.00 & -2.36 & -1.03 & 4.36 & 1.10 & 24.89 & 97.76 \\
\hline 4 & Full Year & variable & 365 & 17 & 1.59 & -2.36 & -1.03 & 3.95 & 0.55 & 12.44 & 88.57 \\
\hline 5 & Full Year & variable & 365 & 9 & 1.42 & -2.35 & -1.03 & 3.77 & 0.28 & 6.33 & 84.53 \\
\hline 6 & Full Year & variable & 365 & 5 & 0.92 & -2.13 & -1.03 & 3.05 & 0.14 & 3.17 & 68.39 \\
\hline \multicolumn{12}{|c|}{ Lengthening Winter Shutdown w/RIW } \\
\hline 1 & Full Year & variable & 365 & 116 & 2.09 & -2.37 & -1.03 & 4.46 & 4.42 & 100 & 100 \\
\hline 2 & Jan-Nov & variable & 334 & 63 & 2.14 & -2.37 & -1.05 & 4.51 & 2.19 & 49.55 & 101.12 \\
\hline 3 & Feb-Oct & variable & 237 & 33 & 1.63 & -2.37 & -1.13 & 4.00 & 1.07 & 24.21 & 89.69 \\
\hline 4 & Mar-Sept & variable & 214 & 16 & 0.84 & -2.36 & -1.26 & 3.20 & 0.50 & 11.31 & 71.75 \\
\hline 5 & Apr-Aug & variable & 153 & 6 & -0.25 & -2.33 & -1.56 & 2.08 & 0.20 & 4.52 & 46.64 \\
\hline 6 & May-Jul & variable & 92 & 3 & -1.71 & -2.29 & -1.98 & 0.58 & 0.07 & 1.58 & 13.00 \\
\hline \multicolumn{12}{|c|}{ Lengthening Summer Shutdown w/RIW } \\
\hline 1 & Full Year & variable & 365 & 116 & 2.09 & -2.37 & -1.03 & 4.46 & 4.42 & 100 & 100 \\
\hline 2 & Jan-May: Aug-Dec & variable & 304 & 49 & 2.14 & -2.01 & -0.58 & 4.15 & 1.62 & 36.65 & 93.05 \\
\hline 3 & Jan-Apr: Sept-Dec & variable & 242 & 16 & 2.00 & -1.08 & -0.03 & 3.08 & 0.53 & 11.99 & 69.06 \\
\hline 4 & Jan-Mar: Oct-Dec & variable & 182 & 4 & 1.65 & 0.15 & 0.73 & 1.50 & 0.12 & 2.71 & 33.63 \\
\hline 5 & Jan-Feb: Nov-Dec & variable & 120 & 1 & 1.43 & 1.43 & 1.67 & - & 0.01 & 0.23 & - \\
\hline 6 & Jan: Dec & variable & 62 & - & - & - & 2.08 & - & 0.002 & - & - \\
\hline \multicolumn{12}{|c|}{ Lengthening Summer and Winter Shutdown w/RIW } \\
\hline 1 & Full Year & variable & 365 & 116 & 2.09 & -2.37 & -1.03 & 4.46 & 4.42 & 100 & 100 \\
\hline 2 & Jan-May: Aug-Nov & variable & 273 & 47 & 2.14 & -2.01 & -0.61 & 4.15 & 1.61 & 36.43 & 93.05 \\
\hline 3 & Feb-Apr: Sept-Oct & variable & 150 & 16 & 1.63 & -1.12 & -0.17 & 2.75 & 0.50 & 11.31 & 61.66 \\
\hline 4 & Mar & variable & 31 & 2 & 0.82 & 0.27 & 0.42 & 0.55 & 0.06 & 1.36 & 12.33 \\
\hline
\end{tabular}




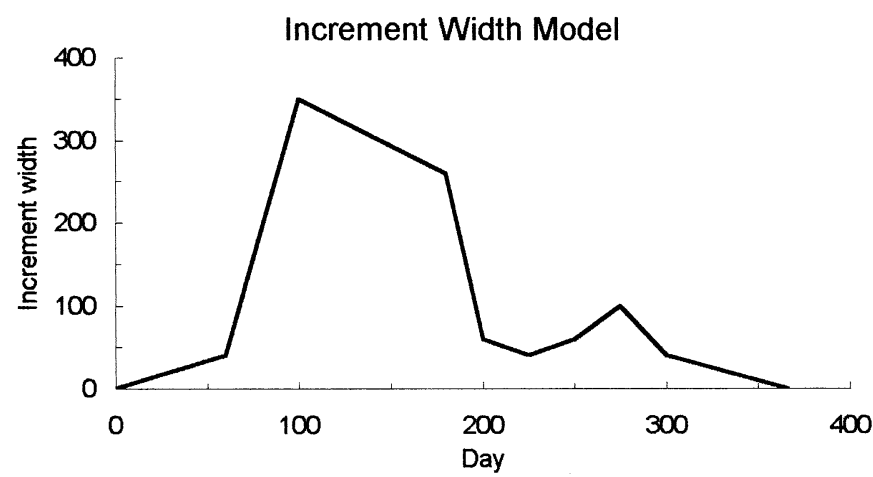

FIGURE 1-Daily increment width model used in the second set of modeled $\delta^{18} \mathrm{O}$ profiles. The model is based on observed intra-annual patterns of shell growth from the northern Gulf of California bivalve mollusk C. cortezi (see Goodwin et al., 2001; Schöne et al., 2002). Increment width in microns.

in the profiles. Although this procedure does not estimate every possible $\delta^{18} \mathrm{O}$ value (running average), it does provide a realistic estimate of potential annual isotope profiles from the hypothetical bivalve shells.

A live specimen of $C$. cortezi was collected from the Colorado River delta in 1995. The bivalve (IP1-A1R; CEAM Research Collection) was sacrificed immediately after collection, and the flesh was removed. In the lab, the right valve was sectioned along the dorso-ventral axis of maximum shell height, and a thick section was mounted to a microscope slide. Sixty-four samples, each with a mass between 50 and 100 micrograms, were drilled from the prismatic layer using a 300-micron drill bit (see Goodwin et al., 2000, for further discussion). In addition, 26 samples from two regions of the thick section were micro-milled according to the procedures described by Dettman and Lohmann (1995). These samples, each 50 microns wide, 150 microns deep, and approximately $5 \mathrm{~mm}$ long, were milled from the nacreous layer of the shell and represent winter growth (see below). All carbonate isotopic analyses were preformed on a Finnigan MAT 252 mass spectrometer equipped with a Kiel III automated sampling device. Samples were reacted with $>100 \%$ orthophosphoric acid at $70^{\circ} \mathrm{C}$. Repeated measurement of standard carbonates resulted in standard deviations of $\pm 0.08 \%$. Results are presented in permil notation with respect to the V-PDB carbonate standard.

A daily increment width profile was measured from the same plane as the $\delta^{18} \mathrm{O}$ samples. The cut valve was polished smooth with 0.3-micron grit and placed in a 0.25 M EDTA solution for one hour. This procedure results in differential dissolution of the daily increments and heightens the con- trast between growth bands and growth intervals (Goodwin et al., 2001; Schöne and Bentley, 2002). Daily increments were photographed under reflected light and daily increment widths were measured from digital images.

\section{RESULTS}

\section{Hypothetical Isotope Profiles}

Two sets of hypothetical stable oxygen isotope profiles are presented. The first set is based on a constant-incrementwidth model, in which each day in a given year has the same daily increment width (Figs. 2A-H; 4A; Table 1). The second set (Figs. 3A-H; 4B; Table 2) incorporates the C. cortezi-increment-width model shown in Figure 1 . Within each set of models, nine profiles are shown: (1) full-year (FY); (2) constant-winter-shutdown (CWS); (3) lengthening-winter-shutdown (LWS); (4) constant-summer-shutdown (CSS); (5) lengthening-summer-shutdown (LSS); (6) reduced-increment-width (RIW); (7) lengthening-winter-shutdown-withreduced-increment-widths (LWSw/RIW); (8) lengtheningsummer-shutdown-with-reduced-increment-widths (LSSw/ RIW); and (9) lengthening-summer-and-winter-shutdownwith-reduced-increment-widths (LSWSw/RIW). In the remainder of this section, each of the nine pairs of models (the corresponding models from each set: constant-increment-width set and the $C$. cortezi-increment-width model set) is described together.

Models without Ontogenetic Decrease in Growth Period: The FY models (Figs. 2A, 3A) contain 365 days of growth in each of their six years (Tables 1 and 2). That is, every day of the bivalve's life is represented by an increment, and all environmental conditions experienced by the bivalve are recorded in its shell. Each model has approximately the same number of samples per year (FY-constant-increment-width: $121 ; \mathrm{FY}-C$. cortezi-incrementwidth model: 116/117). The $\delta^{18} \mathrm{O}$ values in the FY-constant-increment-width model represent three days of growth, while values in the FY-C. cortezi-incrementwidth model represent between one and 42 days. This disparity arises from the daily increment width models used in each profile. Because of the variable daily increment widths in the $C$. cortezi-increment-width model, $\delta^{18} \mathrm{O}$ samples from the relatively fast-growing summer represent as little as a single day, while samples from the slow-growing winter can encompass more than a month.

There are significant differences in the $\delta^{18} \mathrm{O}$ values from the profiles based on the two increment width models. Although the minimum $\delta^{18} \mathrm{O}$ values are identical $(-2.37 \%$ ), the maximum values from the two models differ by $0.09 \%$ (Tables 1 and 2). This difference reflects the influence of

FIGURE $2-\delta^{18} \mathrm{O}$ profiles based on constant-increment-width model: each day in any given year has the same increment width. (A) Full Year (FY) model. Each year contains 365 days of growth. (B) Constant Winter Shutdown (CWS) model. Ten months of each year are represented. No growth occurred in December or January. (C) Lengthening Winter Shutdown (LWS) model. The duration of the winter shutdown increases by two months each year. (D) Constant Summer Shutdown (CSS) model. Ten months of each year are represented. No growth occurred in June or July. (E) Lengthening Summer Shutdown (LSS) model. The duration of the summer shutdown increases by two months each year. (F) Reduced Increment Widths (RIW) model. Every day within any given year has the same width. However, increment widths decreased each year. In the second through sixth year, daily increment widths are one-half as wide as those in the preceding year. (G) Lengthening Winter Shutdown with Reduced Increment Widths (LWSw/RIW) model. Like the LWS model, the duration of the winter shutdown increases by two months each year. However, daily increments also decrease. $(\mathrm{H})$ Lengthening Summer Shutdown with Reduced Increment Widths (LSSw/ RIW) model. This model also incorporates a progressively longer (summer) shutdown with a reduction in daily increment widths. 
A

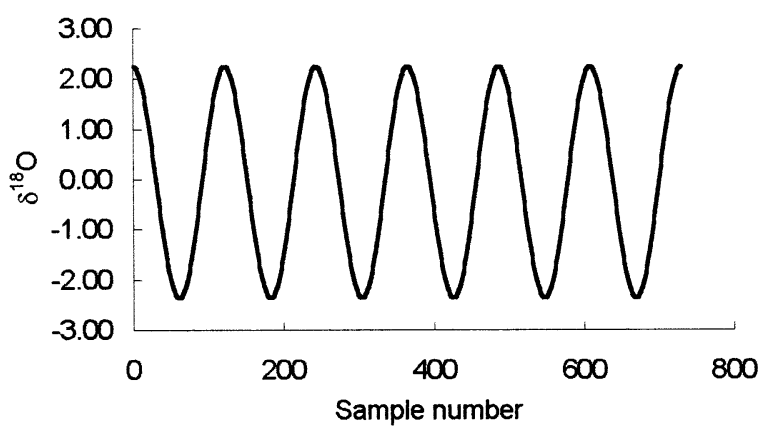

C

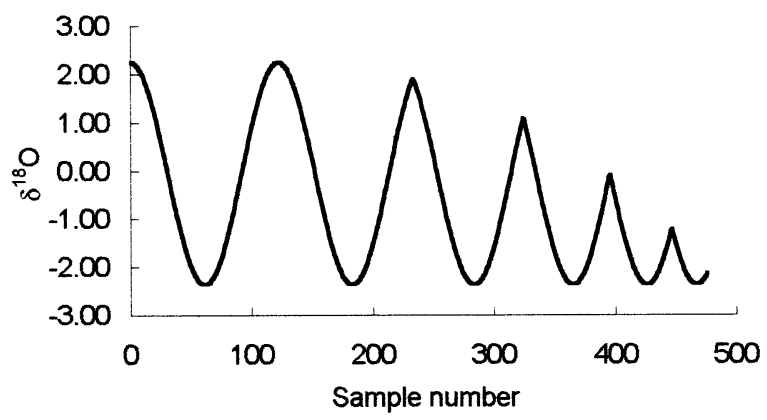

E

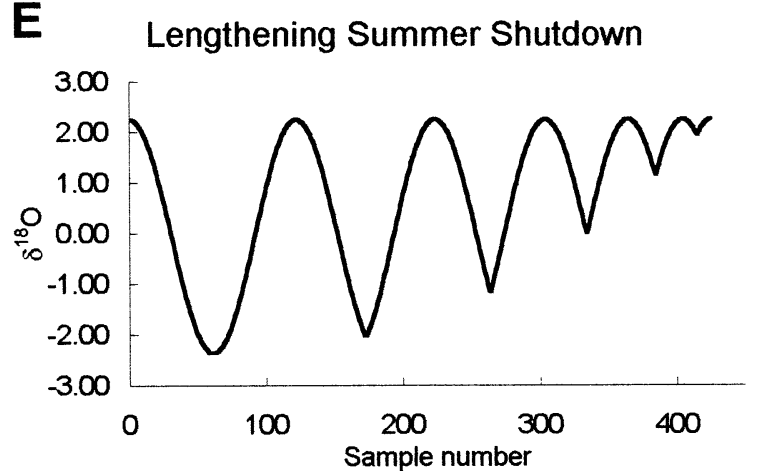

G Lengthening Winter Shutdown w/ RIW

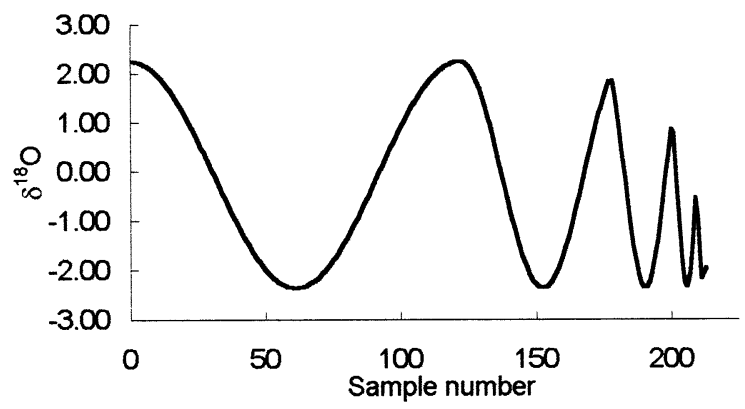

B Constant Winter Shutdown

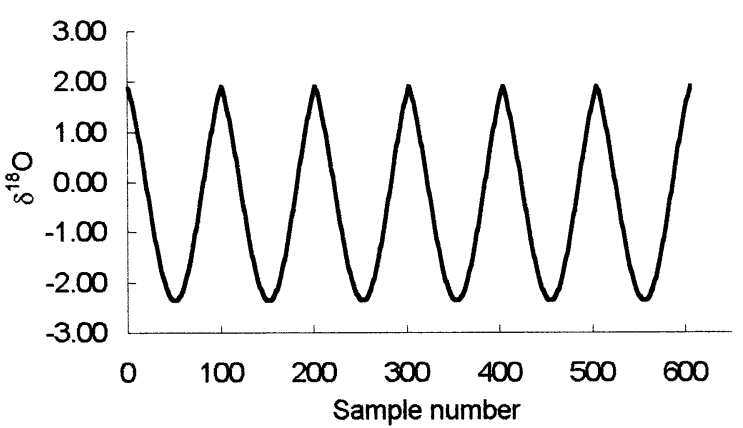

D Constant Summer Shutdown

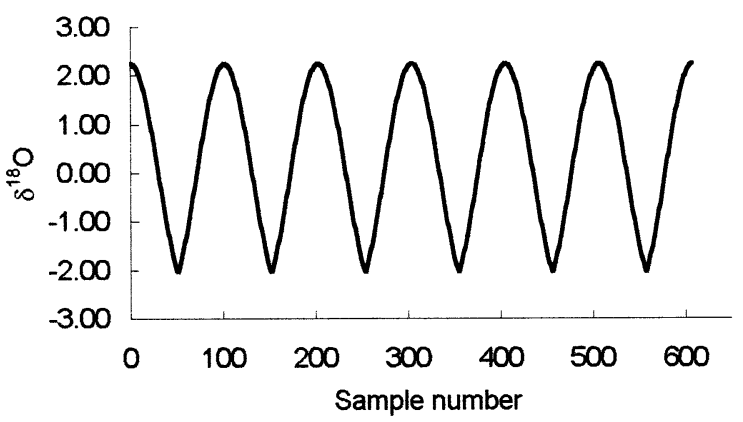

F $\quad$ Reduced Increment Widths

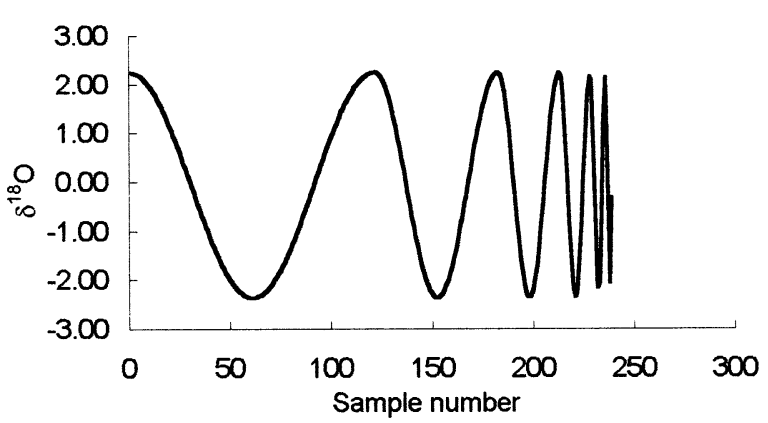

H Lengthening Summer Shutdown w/ RIW

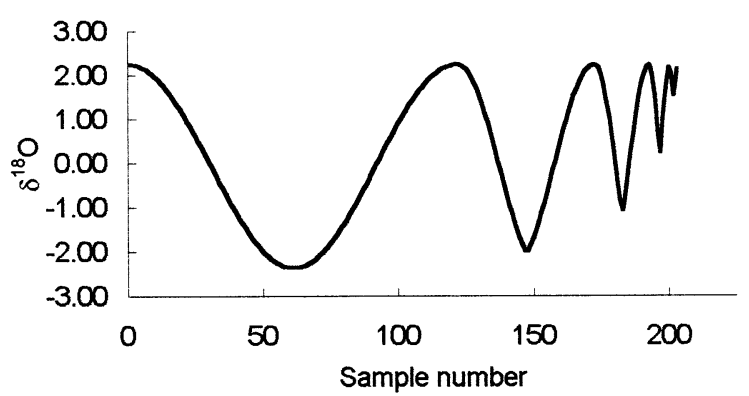


A

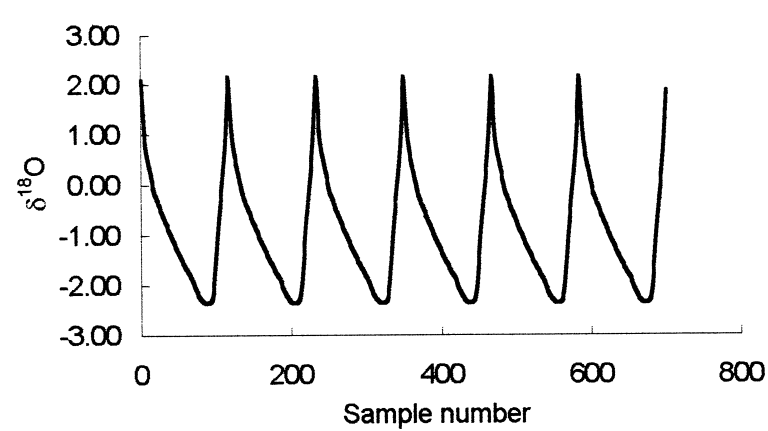

C

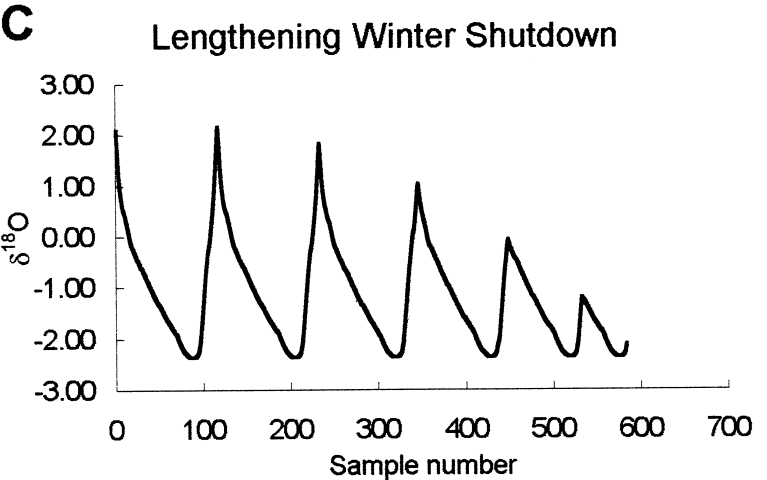

E

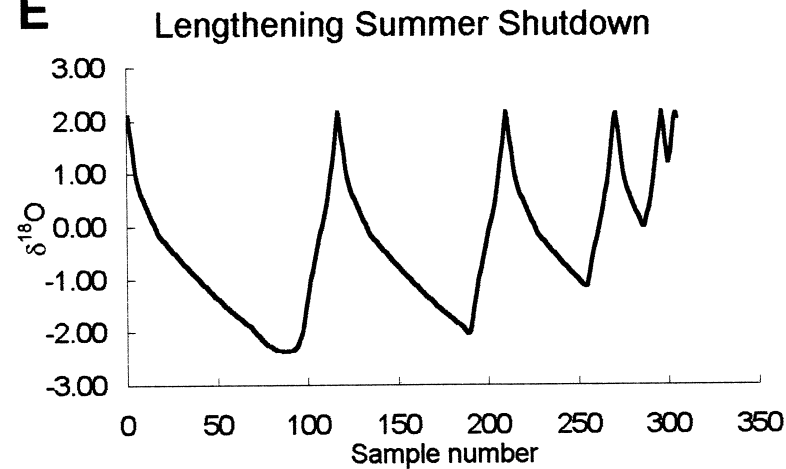

G Lengthening Winter Shutdown w/ RIW

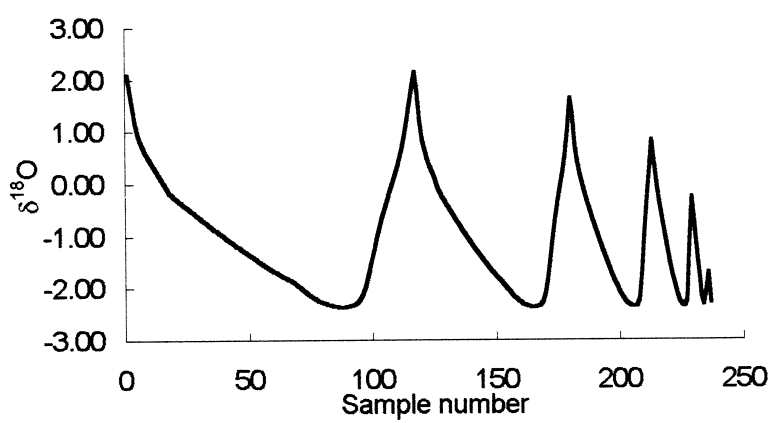

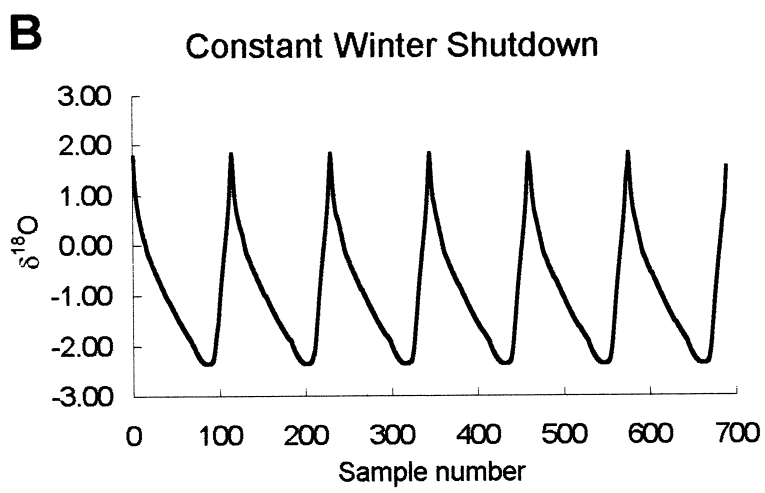

D Constant Summer Shutdown

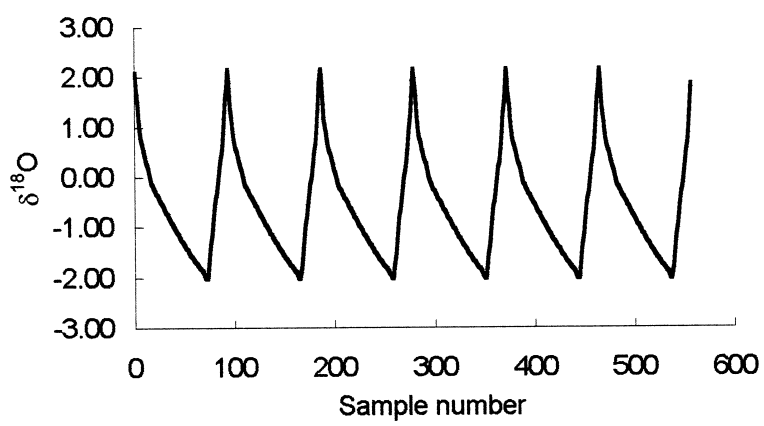

$\mathbf{F}$

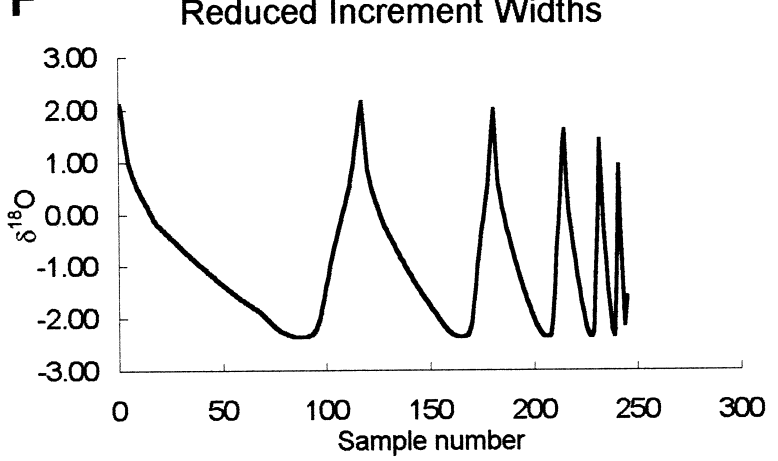

H Lengthening Summer Shutdown w/ RIW

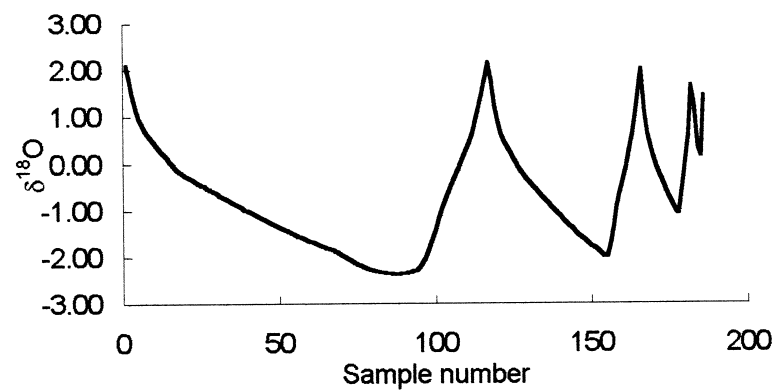

FIGURE $3-\delta^{18} \mathrm{O}$ profiles that incorporate a simplified daily increment width model based on the intra-annual growth of $C$. cortezi (Fig. 1 ). Model parameters for $(\mathrm{A})$ through $(\mathrm{H})$ are described in Figure 2 caption. 
TABLE 3-Data from the observed 300-micron $\delta^{18} \mathrm{O}$ profile from the bivalve collected alive from the northern Gulf of California.

\begin{tabular}{|c|c|c|c|c|c|c|c|c|}
\hline $\begin{array}{l}\text { Ontogenetic } \\
\text { year }\end{array}$ & $\begin{array}{l}\text { Calendar } \\
\text { year }\end{array}$ & Max. $\delta^{18} \mathrm{O}$ & Min. $\delta^{18} \mathrm{O}$ & Amp. $\delta^{18} \mathrm{O}$ & $\begin{array}{l}\text { Cumulative } \\
\text { growth }(\mathrm{mm})\end{array}$ & $\begin{array}{c}\text { Annual } \\
\text { growth }(\mathrm{mm})\end{array}$ & \# Incs. & $\begin{array}{l}\text { Max. inc. } \\
\text { width }(\mu \mathrm{m})\end{array}$ \\
\hline 1 & 1989 & - & - & - & 6.50 & 6.50 & - & - \\
\hline 2 & 1990 & 0.95 & -2.23 & 3.18 & 48.25 & 41.75 & 329 & 346 \\
\hline 3 & 1991 & 0.91 & -2.47 & 3.38 & 69.60 & 21.35 & 243 & 272 \\
\hline 4 & 1992 & 0.71 & -2.43 & 3.14 & 80.90 & 11.30 & 184 & 176 \\
\hline 5 & 1993 & -0.17 & -3.10 & 2.93 (1.77) & 88.00 & 7.10 & 124 & 164 \\
\hline 6 & 1994 & -0.73 & -2.41 & 1.69 & 91.00 & 3.00 & - & - \\
\hline 7 & 1995 & -1.48 & -2.76 & $1.28(1.02)$ & 93.65 & 2.65 & - & - \\
\hline
\end{tabular}

the C. cortezi-increment-width model's narrow winter daily increments. Because many more of these narrow daily increments fit into a single 300-micron drill hole, their average value is farther from the maximum winter value of $2.24 \%$ in the constant increment width model. In addition, the annual averages from the models are different (FYconstant-increment-width model: $-0.06 \%$; FY-C. corteziincrement-width model:-1.03\%o). The more negative annual average results from the increased proportion of annual growth during the summer in the FY-C. cortezi-increment-width model.

The CWS models (Figs. 2B, 3B) show the profiles expected if the bivalves did not grow in December or January, while the CSS models (Figs. 2D, 3D) show the profiles from bivalves that did not grow in June or July. Like the FY models, the CWS models and CSS models do not have a varying ontogenetic growth rate. These models essentially are truncated versions of their FY counterparts, and as such have reduced amplitudes due to more-negative winter values and more-positive summer values, respectively (Tables 1 and 2).

Models with Ontogenetic Decrease in Growth Period: The LWS models (Figs. 2C, 3C) accommodate the decrease in growth rate by progressively shortening the growth period. The length of the winter shutdown becomes longer each year; therefore, each year in the profile has smaller annual isotopic amplitude than the preceding year (Tables 1 and 2). Because the shutdowns occur in the winter, the most positive values in each year decrease, but the summer values in each year remain constant. Thus, the isotopic amplitudes are truncated at the positive (winter) end. Furthermore, as winter growth becomes a smaller and smaller component of each year's growth, the annual average $\delta^{18} \mathrm{O}$ values become more negative (Tables 1 and 2).

The LSS models (Figs. 2E, 3E) have similarly decreasing growth periods. Unlike the LWS models, these models have progressively longer shutdowns during the summer (Tables 1 and 2). Again, each year in these profiles has smaller isotopic amplitude than the year before. The annual isotopic amplitudes, however, are truncated at the negative (summer) end. In each year, the proportion of growth that occurs in the summer decreases, leading to more positive annual average $\delta^{18} \mathrm{O}$ values.

In all four of the above lengthening-shutdown profiles, each of the six modeled years is represented by multiple $\delta^{18} \mathrm{O}$ samples. However, the number of samples per year decreases in each model. In fact, the sixth year of the LSS model, which incorporates the $C$. cortezi-increment-width model (Fig. 3E), is represented by only two samples (Table 3).

The RIW models (Figs. 2F, 3F) incorporate the ontoge- netic decrease in annual growth, not by shortening the growth period, but rather by progressively narrowing the daily increment widths each year. The increment-width reduction is reflected in the decrease in annual growth rate (\% First Year Growth; Tables 1 and 2). In both models, the annual amplitudes decrease through ontogeny. Unlike the LWS and LSS models, whose amplitudes are truncated either at the positive or the negative end, the RIW models have amplitudes that decrease by truncation at both ends. However, their amplitude reduction is not as pronounced as in the LSS or LWS models. In the RIW model, in which each day of the year has the same width (Fig. 2F), the isotopic amplitude in the second and third years is $99.78 \%$ of the first year (Table 1). By the sixth year, when annual growth has been reduced nearly $97 \%$, the amplitude reduction is less than $10 \%$. A similar pattern is seen in the RIW model that uses the $C$. cortezi-increment-width model (Fig. 3F; Table 2). Because the amplitudes are truncated symmetrically, the average annual values remain relatively constant through ontogeny (Tables 1 and 2).

Models with Decreasing Growth Period and Reduced Increment Widths: Because the LWSw/RIW models (Figs. $2 \mathrm{G}, 3 \mathrm{G}$ ) incorporate progressively shorter growth periods and narrower increments, their isotopic amplitude reduction is more pronounced than any models discussed so far. These models have annual minimum values similar to the RIW models. However, their annual maximum values in years 3 through 6 are less than in the RIW models (see Tables 1 and 2). Thus, because their maximum values decrease more rapidly, the LWSw/RIW models have smaller annual isotopic amplitudes than either the LWS or RIW models (Tables 1 and 2). In addition, in the first set of models (those with constant increment widths), the final year of the LWSw/RIW model is represented by a single sample, and thus has no amplitude (Table 1). Furthermore, despite the fact that the sixth year is represented (Table 1 ), only five years of growth are apparent in the hypothetical profile (Fig. $2 \mathrm{G}$ ).

The LSSw/RIW models (Figs. $2 \mathrm{H}, 3 \mathrm{H}$ ) also have a rapid rate of amplitude reduction. These models have annual maximum values similar to the RIW models, but have minimum values that increase more quickly. Therefore, their amplitude reduction is accomplished predominantly by truncation of minimum values.

In addition to rapid amplitude reduction, the effects of progressively longer summer shutdowns and reduced increment widths are seen in the $\delta^{18} \mathrm{O}$ profiles. In Figure $2 \mathrm{H}$ only five years are visible despite the fact that six years of growth were modeled. This pattern is even more pronounced in the LSSw/RIW model that incorporates the $C$. 


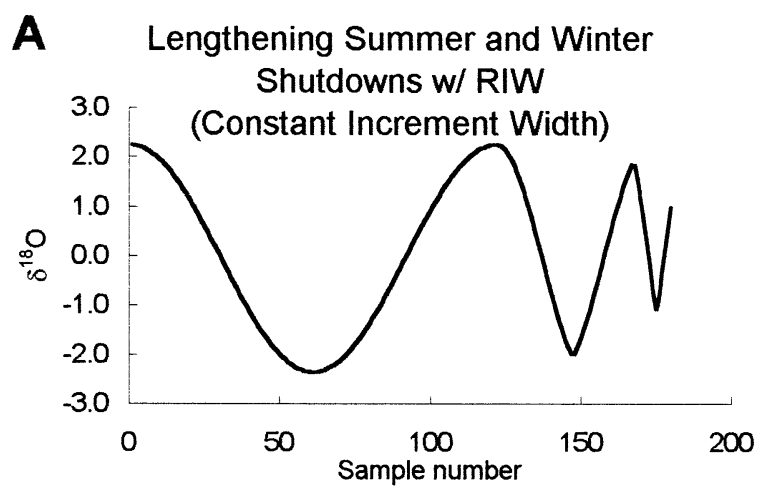

B Lenghtening Summer and Winter Shutdowns w/ RIW

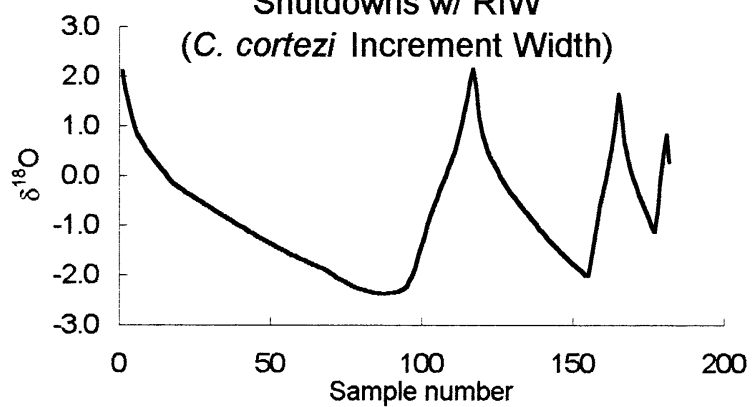

FIGURE $4-\delta^{18} \mathrm{O}$ profiles from the Lengthening Summer and Winter Shutdown with Reduced Increment Widths (LSWSw/RIW) model. (A) Profile using the constant-increment-width model. B) Profile using the C. cortezi-increment-width model.

cortezi-increment-width model (Fig. 3H), where only four years are apparent.

Only four years of growth were calculated in the LSWSw/RIW models (Figs. 4A, B; Tables 1 and 2). Combining the effects of lengthening summer shutdowns, lengthening winter shutdowns, and reduced increment widths results in models with the most rapid amplitude attenuation. By the fourth year, the amplitude of the LSWSw/RIW-C. cortezi-increment-width model is reduced by nearly $90 \%$ (Table 2 ). In contrast, the greatest fourthyear amplitude reduction in this set of models is $\sim 65 \%$ (LSSw/RIW; Table 2). Furthermore, the final year in the LSWSw/RIW-constant-increment-width model is represented by only one sample (Table 1).

\section{Observed Isotope Profiles}

In specimen IP1-A1R, sixty-four, 300-micron $\delta^{18} \mathrm{O}$ samples, drilled from the outer shell layer along the axis of maximum growth between the umbo and commissure, define growth that occurred in seven calendar years (Fig. 5). The winter peaks (the most positive values) decrease monotonically through the bivalve's ontogeny, while the summer values remain relatively constant (Fig. 5; Table 3 ). The only exceptions are 1993 and 1995, when the minimum values are more negative than the expected summer values of approximately $-2.5 \%$.

Micro-milled samples are from regions of the nacreous layer deposited in late fall and early spring. The first set of samples $(n=14)$ represents growth in late 1992 and early
A

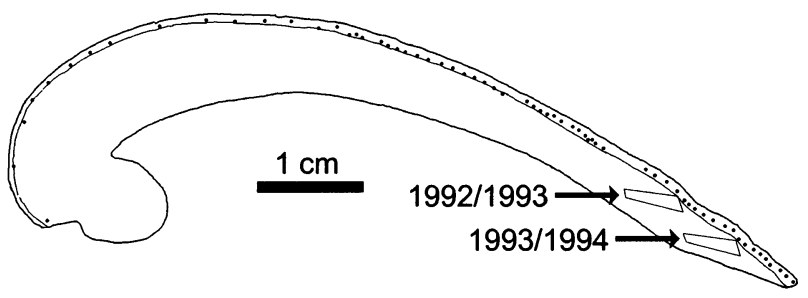

B

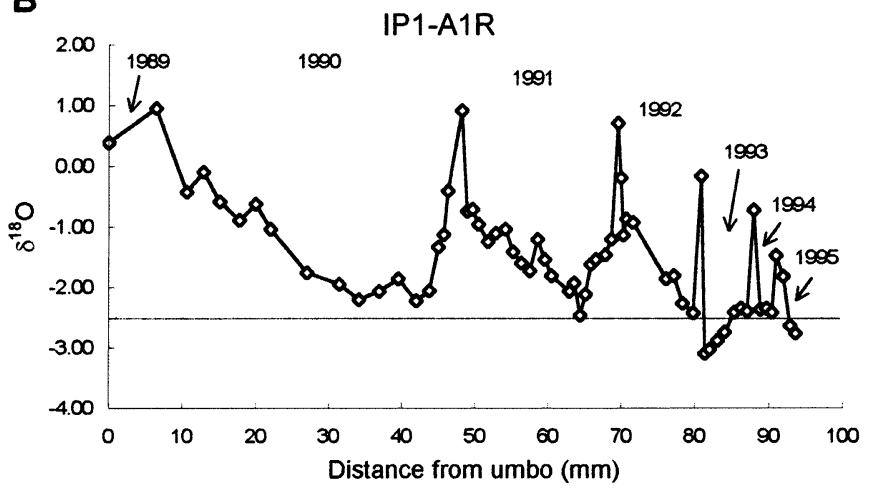

FIGURE 5-Line drawing of sampled specimen and its $\delta^{18} \mathrm{O}$ profile. (A) Line drawing of shell cross-section (IP1-A1R) showing the position of isotopic samples. Samples were drilled using a 300-micron drill bit. The two micro-milled regions are also shown. (B) $\delta^{18} \mathrm{O}$ profile from the same specimen. Note the declining winter values through ontogeny. The horizontal line at $-2.5 \%$ marks the expected summer values. $\delta^{18} \mathrm{O}$ values below this line (1993 and 1995) reflect the influence of isotopically light Colorado River water. See text for discussion.

1993 (Fig. 6A). These samples define a positive winter peak correlative with the 1992/1993 winter peak in Figure 5 . The most positive sample from this set is $0.51 \%$, which is $0.68 \%$ more positive than the $1992 / 1993$ winter peak in the 300 micron profile (see Table 3). The second set of micro-milled samples $(n=12)$ is from shell deposited in the fall of 1993 and spring of 1994 (Fig. 6B). The most positive sample from this set is $-0.38 \%$, which is $0.35 \%$ more positive than the correlative winter peak in the 300-micron profile (see Table 3).

\section{Daily Increment Width Profile}

Daily increments were counted and measured from the umbo end toward the ventral margin of the live specimen, IP1-A1R. Counting increments began at the approximate position of the earliest growth in 1990. Thus, increments represent growth in the bivalve's first four full years of life (Fig. 7). The annual increment width profiles are similar to profiles from other C. cortezi from the northern Gulf of California (Goodwin et al., 2001). The four years measured show the same general pattern-the first increments in each year are narrow, followed by increments whose widths increase rapidly. Increment widths gradually decrease following those with the greatest widths. The beginning of the second half of each year is marked by very narrow increments. Following this interval, increment widths rebound slightly, and finally decrease at the end of the year. The number of daily increments counted each year decreases as the duration of the growth period short- 

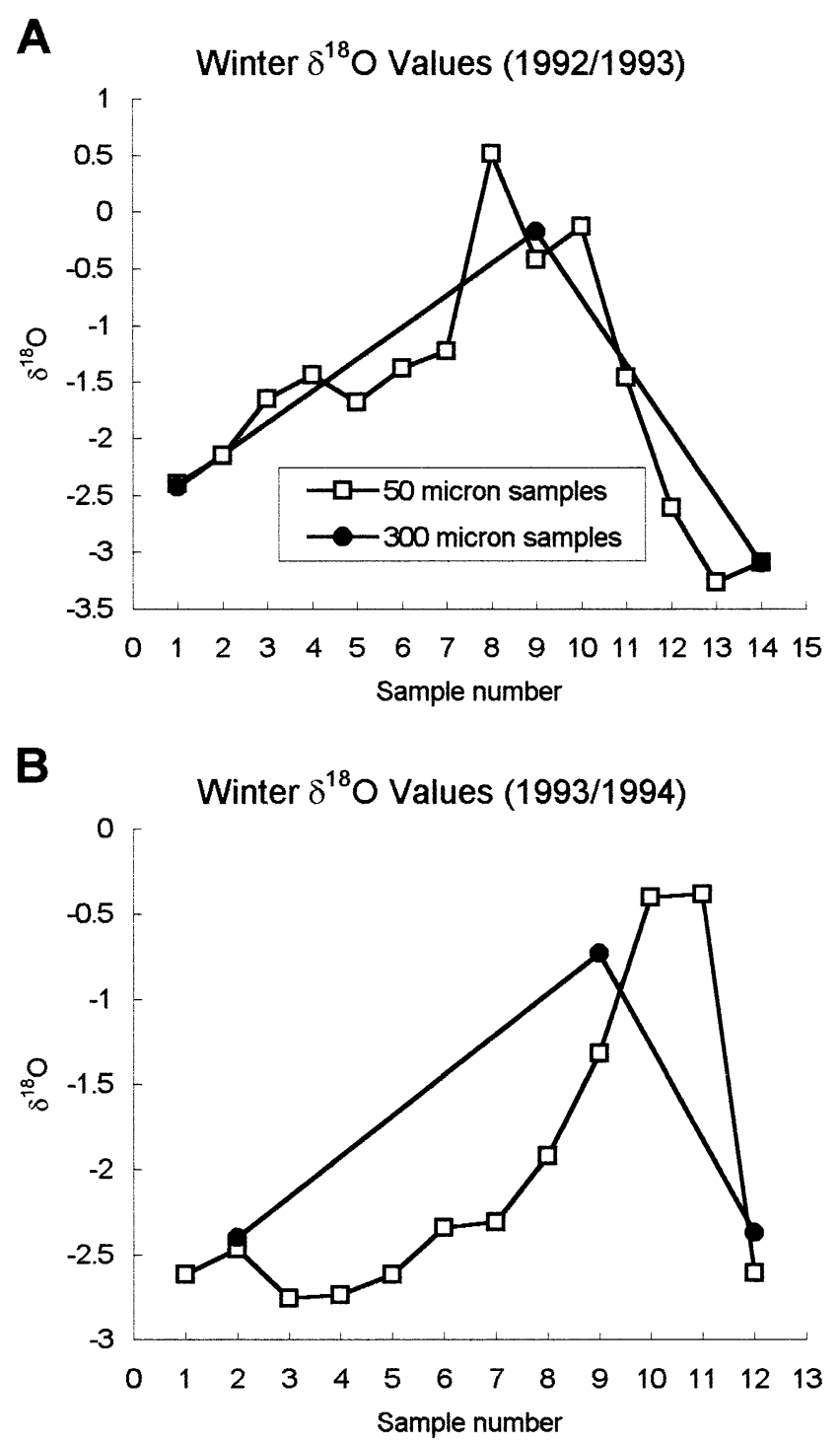

FIGURE 6-300-micron and 50-micron samples from IP1-A1R. (A) Winter 1992/1993. (B) Winter 1993/1994.

ens through ontogeny, and daily increment widths decrease each year (Table 3).

\section{SUMMARY OF PATTERNS IN THE MODELS}

Two general patterns emerge from both sets of models (those with constant-increment widths and those with the C. cortezi-increment widths). First, models that do not incorporate a decrease in ontogenetic growth rate (FY, CWS, and CSS) have constant annual amplitudes (Table 4). FY models have the greatest amplitudes through their ontogeny. CWS and CSS models have approximately equal amplitudes, which are smaller than in the FY models (Tables 1 and 2). This difference reflects the shorter growth periods in the CWS and CSS models. In addition, the summer $\delta^{18} \mathrm{O}$ values in the CWS model are equal to the FY model. Similarly, the winter values in the CSS model are identical to those in the FY model.

Second, models that incorporate a declining ontogenetic growth rate have progressively fewer samples per year and small amplitudes through ontogeny (Table 4). During every year of the bivalve's life, less shell material is added along the axis of maximum shell height. Thus, fewer 300micron samples can be collected within the years from the latter stages of growth (see Table 1 and 2). Furthermore, as growth slows, a smaller proportion of the annual $\delta^{18} \mathrm{O}$ variation is recorded in the shell. Early in the bivalve's ontogeny, this process results in relatively minor amplitude reduction. However, later in life, the effects can be large. Figures 2, 3, and 4 show that the degree of amplitude attenuation is highly variable. These differences result from the varying contributions of shortening growth periods, reduction in increment width, or both (see below).

Despite similarities between the two sets of models, there is an important difference in their $\delta^{18} \mathrm{O}$ profile shapes. Recall that the profiles in the two sets of models were constructed in exactly the same way, except for the daily increment width model. In the first set, all of the daily increments within each year were identical. However, the second set of models incorporated an intra-annual variation in increment width that is based on the growth patterns of $C$. cortezi from the northern Gulf of California. This variation results in cuspate, rather than sinusoidal, $\delta^{18} \mathrm{O}$ profiles (compare Figure $2 \mathrm{~A}$ with $3 \mathrm{~A}$ ).

\section{DISCUSSION}

\section{Modeled $\delta^{18} \mathrm{O}$ Profiles}

The models show that an ontogenetic decrease in growth rate causes annual isotopic amplitudes to become smaller through the bivalve's life, even when annual environmental cycles remain constant (Table 4). This pattern is common in geochemical records from bivalve shells (Jones et al., 1983; Jones et al., 1989; Weidman et al., 1994).

Which is more important in decreasing annual isotopic amplitudes: shorter growth periods or decreasing increment widths? Figures 8A and 9A show that the number of samples per year decreases faster in the RIW model than in either the LWS or LSS models. However, the maximum $\delta^{18} \mathrm{O}$ value changes more rapidly in the LWS models than in the RIW models (Figs. 8B, 9B). Similarly, the minimum $\delta^{18} \mathrm{O}$ values increase faster in the LSS models than in the RIW models (Figs. 8C, 9C). The pattern also is seen in the average $\delta^{18} \mathrm{O}$ values (Figs. 8D, 9D). Thus, in spite of the fact that fewer samples occur in each year of the RIW model, maximum and minimum $\delta^{18} \mathrm{O}$ are more sensitive to the timing of growth halts.

The influence of growth period duration is apparent in the graphs of annual $\delta^{18} \mathrm{O}$ amplitude (Figs. 8E, 9E). The LWS and LSS models both have more rapidly decreasing amplitudes than the RIW model. This observation is not surprising because amplitude depends on maximum and minimum values.

This is not to say that the length of the growth period is always more important than increment width reduction. In the models presented here, the length of shutdown was based on the growth period observed in shells from the northern Gulf (see Figure 7; Table 3). However, shorter growth cessations (longer growth periods) could have been chosen. For example, if the growth period were shortened two days a year (rather than two months), the proportion 


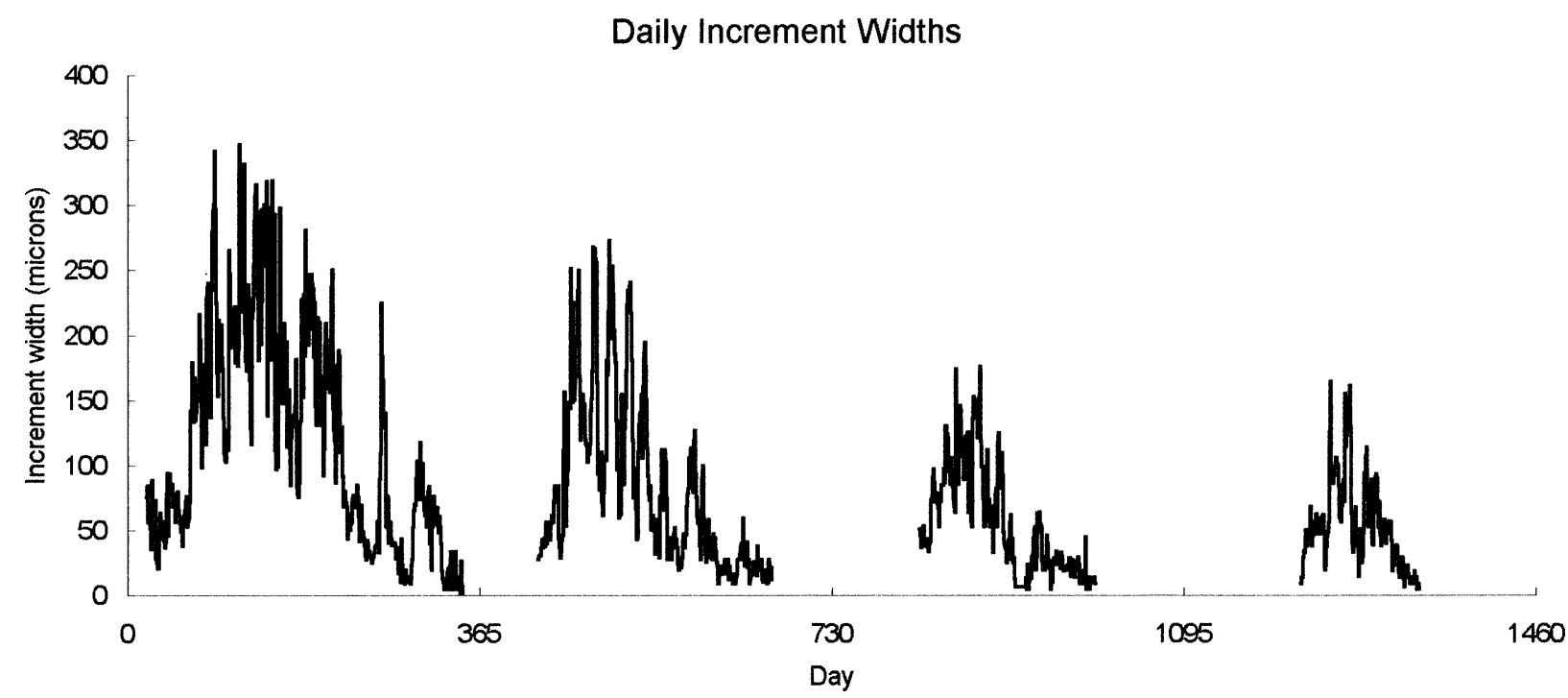

FIGURE 7-Daily increment widths from IP1-A1R. The daily increment width profile from each of the four years has been centered on the midpoint of the respective calendar year. Note that the number and width of daily increments decreases through the bivalve's ontogeny.

of amplitude reduction associated with decreasing growth periods would be relatively minor.

Combining the effects of shorter growth periods with reduced increment widths has an even more pronounced effect on the reduction in amplitude. In Figures $8 \mathrm{E}$ and $9 \mathrm{E}$, the LWSw/RIW and LSSw/RIW models show an even faster rate of amplitude reduction than their model counterparts without reduced increment widths.

The LSWSw/RIW models have the fastest amplitude attenuation of all the models (Figs. 8F, 9F). Recall that the growth period in these models was shortened due to shutdowns in both the summer and winter. This model also combines the effects of summer and winter shutdowns with reduced increment widths. An important consequence of this is that, by the fourth year, the amplitude is reduced by $100 \%$ and $\sim 90 \%$ in the constant-increment-width and C. corteziincrement-width models, respectively (Figs. 8F, 9F). Thus, multiple intra-annual growth cessations can have a large effect on amplitude reduction through ontogeny.

In spite of the similar patterns in the two sets of models, important differences are evident between the models incorporating the two increment width models. The most obvious difference is the change in the shape of the $\delta^{18} \mathrm{O}$ profiles. The FY model in the constant-increment-width model set is a sinusoid (Fig. 2A). This pattern is expected given the sinusoidal temperature model and constant daily increment widths. The FY model in the $C$. cortezi-incrementwidth set, however, is cuspate (Fig. 3A). The most positive (winter) values in the profile form sharp peaks. The negative (summer) values form more rounded "U" shapes. This

TABLE 4-General trends observed in the modeled $\delta^{18} \mathrm{O}$ profiles.

\begin{tabular}{|c|c|c|c|c|c|}
\hline Model & \# Samples & $\begin{array}{c}\text { Max. } \delta^{18} \mathrm{O} \\
\text { value }\end{array}$ & $\begin{array}{c}\text { Min. } \delta^{18} \mathrm{O} \\
\text { value }\end{array}$ & $\begin{array}{c}\text { Avg. } \delta^{18} \mathrm{O} \\
\text { value }\end{array}$ & $\begin{array}{c}\text { Annual } \delta^{18} \mathrm{O} \\
\text { amplitude }\end{array}$ \\
\hline \multicolumn{6}{|l|}{ Constant-increment-width models: } \\
\hline Full Year & constant & constant & constant & constant & constant \\
\hline Constant Winter Shutdown & constant & constant & constant & constant & constant \\
\hline Lengthening Winter Shutdown & decreasing & decreasing & constant & decreasing & decreasing \\
\hline Constant Summer Shutdown & decreasing & constant & constant & constant & constant \\
\hline Lengthening Summer Shutdown & decreasing & constant & increasing & increasing & decreasing \\
\hline Reduced Increment Widths & decreasing & constant & constant & increasing & decreasing \\
\hline Lengthening Winter Shutdown w/RIW & decreasing & decreasing & constant & decreasing & decreasing \\
\hline Lengthening Summer Shutdown w/RIW & decreasing & constant & increasing & increasing & decreasing \\
\hline Lengthening Summer and Winter Shutdown w/RIW & decreasing & decreasing & increasing & increasing & decreasing \\
\hline \multicolumn{6}{|l|}{ C. cortezi-increment-width models: } \\
\hline Full Year & constant & constant & constant & constant & constant \\
\hline Constant Winter Shutdown & constant & constant & constant & constant & constant \\
\hline Lengthening Winter Shutdown & decreasing & decreasing & constant & decreasing & decreasing \\
\hline Constant Summer Shutdown & constant & constant & constant & constant & constant \\
\hline Lengthening Summer Shutdown & decreasing & constant & increasing & increasing & decreasing \\
\hline Reduced Increment Widths & decreasing & decreasing & constant & constant & decreasing \\
\hline Lengthening Winter Shutdown w/RIW & decreasing & decreasing & constant & decreasing & decreasing \\
\hline Lengthening Summer Shutdown w/RIW & decreasing & decreasing & increasing & increasing & decreasing \\
\hline Lengthening Summer and Winter Shutdown w/RIW & decreasing & decreasing & increasing & increasing & decreasing \\
\hline
\end{tabular}



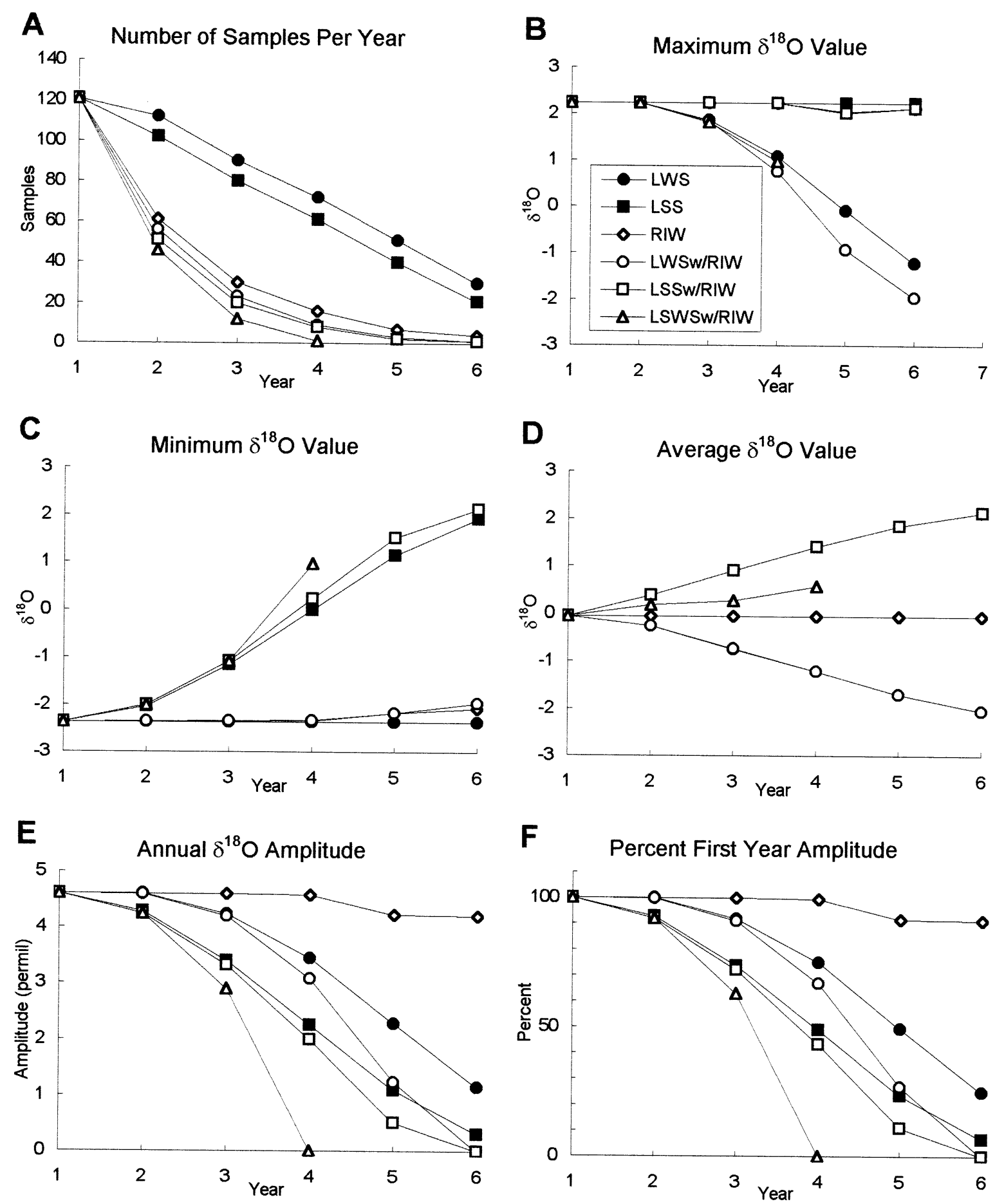

FIGURE 8-Graphs showing the patterns of variation from $\delta^{18} \mathrm{O}$ profiles using the constant-increment-width model. LWS (filled circles): Lengthening Winter Shutdown model; LSS (filled squares): Lengthening Summer Shutdown model; RIW (open diamonds): Reduced Increment Widths model; LWSw/RIW (open circles): Lengthening Winter Shutdown with Reduced Increment Widths model; LSSw/RIW (open squares): Lengthening Summer Shutdown with Reduced Increment Widths model; LSWSw/RIW (open triangles): Lengthening Summer and Winter Shutdown with Reduced Increment Widths model.

pattern arises from the variation in the daily increment widths, and the resulting change in sample resolution. Unlike $\delta^{18} \mathrm{O}$ samples from the constant-increment-width model set, 300-micron samples in the $C$. cortezi-incrementwidth model set contain different numbers of daily increments. For example, the first sample from the FY model contains 30 daily increments. However, in early April through late May (days 93 through 144), when daily increment widths are greater than 300 microns (Fig. 1), each sample represents less than a day of growth.

A year-to-year change in the sample resolution modifies the shape of the $\delta^{18} \mathrm{O}$ profile. If each sample represented a 

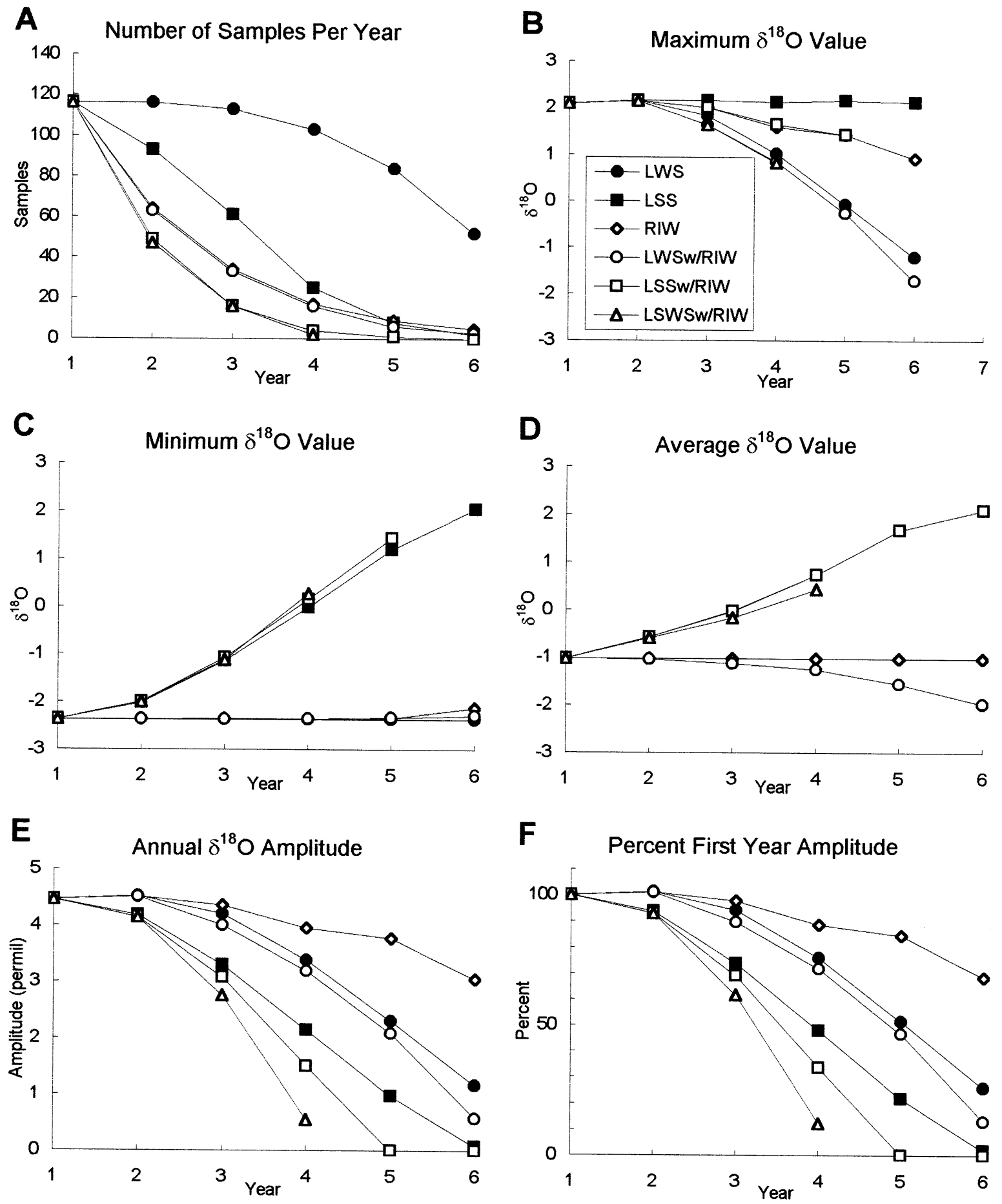

FIGURE 9-Graphs showing the patterns of variation from $\delta^{18} \mathrm{O}$ profiles using the $C$. cortezi-increment-width model. LWS (filled circles): Lengthening Winter Shutdown model; LSS (filled squares): Lengthening Summer Shutdown model; RIW (open diamonds): Reduced Increment Width model; LWSw/RIW (open circles): Lengthening Winter Shutdown with Reduced Increment Width model; LSSw/RIW (open squares): Lengthening Summer Shutdown with Reduced Increment Width model; LSWSw/RIW (open triangles): Lengthening Summer and Winter Shutdown with Reduced Increment Width model.

single day, then the $\delta^{18} \mathrm{O}$ profile would be a sinusoid. Furthermore, when each sample in a profile contains the same number of days, the result is a sinusoidal $\delta^{18} \mathrm{O}$ profile (e.g., FY models with constant daily increment widths; Figure 2A). As the number of days in each sample increas- es, the profile retains its sinusoid shape. However, the amplitude decreases. The RIW model (Fig. 2F) illustrates this phenomenon.

Continued coarsening of sample resolution changes the shape of the $\delta^{18} \mathrm{O}$ profile so that its sinusoidal shape is no lon- 


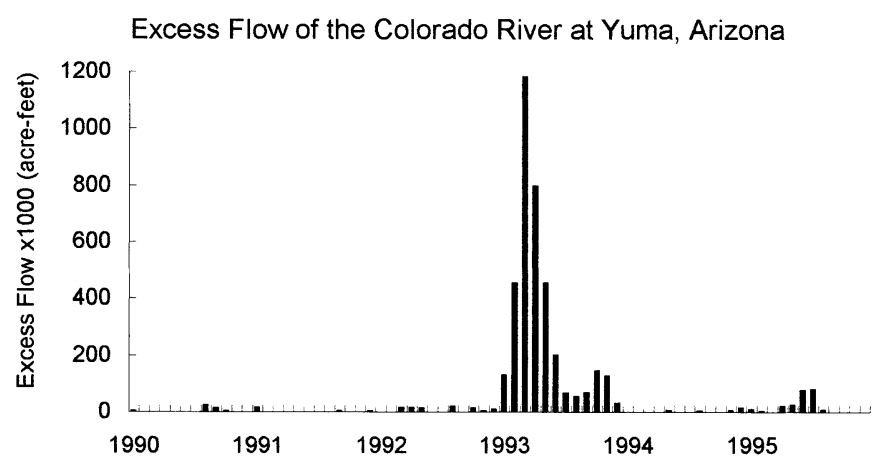

FIGURE 10-Histogram showing the Colorado River flows in excess of treaty obligations at Yuma, Arizona (Leon Martin: Bureau of Reclamation, pers. comm., November 2000).

ger recognizable. The winter values form a sharp peak in the FY-C. cortezi-increment-width model (Fig. 3A). The most positive $\delta^{18} \mathrm{O}$ values in this profile encompass 42 days of growth and have the coarsest resolution of the entire profile. In contrast, the most negative part of the profile has the finest resolution ( $~ 1$ day per sample) and is a smooth curve reminiscent of the shape of the summer values in the FYconstant-increment-width model (Fig. 2A). Thus, despite the smooth sinusoidal temperature profile, changing intra-annual widths produces a $\delta^{18} \mathrm{O}$ profile with a cuspate shape.

This observation is important because cuspate profiles have been used to identify growth halts (Jones et al., 1983). The other criterion often used to identify growth halts is winter (or summer) $\delta^{18} \mathrm{O}$ values less extreme than expected (Jones et al., 1983). Recall that the most positive winter values in the FY-C. cortezi-increment-width model are $0.9 \%$ more negative than the winter values in the FYconstant-increment-width model (Tables 1 and 2). Furthermore, if the daily increments in the winter were narrower, or a drill bit with a diameter larger than $300 \mathrm{mi}-$ crons were used, this discrepancy would be even greater. Thus, in addition to the profile's cuspate shape, this observation would suggest that a growth halt had occurred. This conclusion, however, would be incorrect for the FY-C. cortezi-increment-width model (Fig. 3A). This profile is based on a model with continuous growth in which the cuspate shape and anomalous $\delta^{18} \mathrm{O}$ values are artifacts of changing sample resolution. Thus, while cuspate profiles and $\delta^{18} \mathrm{O}$ discrepancies often are associated with growth halts, profiles with these characteristics also can result from sampling shells that grew continuously, but have intra-annual increments with varying widths.

\section{Observed $\delta^{18} \mathrm{O}$ Profile}

The $\delta^{18} \mathrm{O}$ profile from a bivalve that lived in the northern Gulf of California (Fig. 5) shows many of the same patterns seen in the modeled profiles. This specimen was collected alive in 1995. The number of annual increments on the surface of the shell suggests that the bivalve began growing in 1989. This conclusion is confirmed by the six cycles in the $\delta^{18} \mathrm{O}$ profile (Fig. 5).

The $\delta^{18} \mathrm{O}$ profile shows decreasing isotopic amplitudes through ontogeny. This reduction is accomplished primarily by the reduction of peak winter values. The summer values remain relatively constant and near the expected

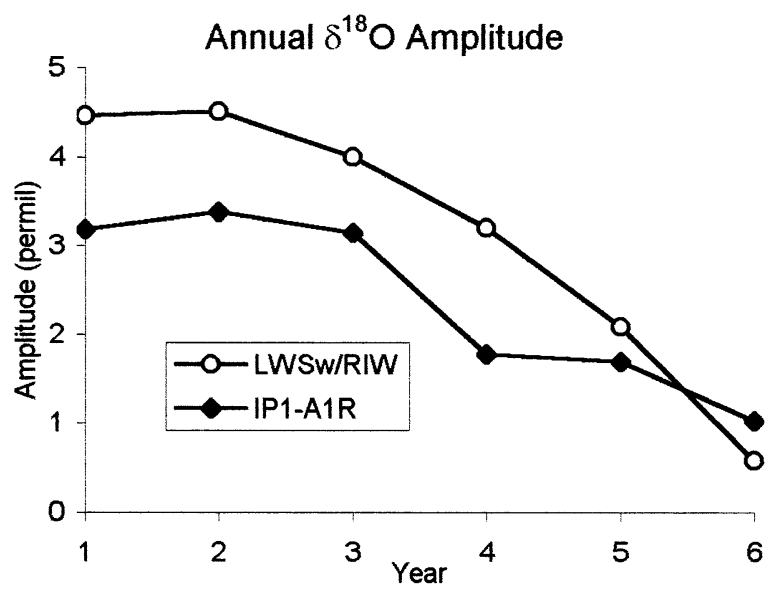

FIGURE $11-$ Comparison of annual $\delta^{18} \mathrm{O}$ amplitudes between the Lengthening Winter Shutdown with Reduced Increment Widths (LWSw/RIW) model and IP1-A1R.

summer values $(\sim-2.5 \%)$ for bivalves from the northern Gulf of California.

The only exceptions occur in 1993 and 1995, when summer $\delta^{18} \mathrm{O}$ values are more negative than expected. These anomalous values are likely the result of the influx of Colorado River water, which has a $\delta^{18} \mathrm{O}$ value significantly more negative than seawater. Figure 10 shows flow of the Colorado River in excess of US/Mexico treaty obligations (Leon Martin: Bureau of Reclamation, pers. comm., November 2000). In 1990 through 1992, very little excess water was delivered to Mexico. In these years, the minimum $\delta^{18} \mathrm{O}$ values were at or near expected values. However, in 1993 large quantities were delivered to Mexico and ultimately to the Colorado River delta. This influx of river water is reflected in the $\delta^{18} \mathrm{O}$ profile by summer values more negative than would normally be expected. Again, in 1994, little excess flow occurred and summer $\delta^{18} \mathrm{O}$ values were at expected values. Finally, in 1995, immediately prior to the bivalve's collection, a small quantity of water was delivered, resulting in more negative $\delta^{18} \mathrm{O}$ values than expected. The correlation of summer $\delta^{18} \mathrm{O}$ values and river flux indicates that these bivalves are reliable recorders of years with anomalously high river flow.

As was shown in the modeled profiles, reduction of annual amplitude is a function of shorter growth periods, reduced increments, or both. Recall that in the bivalve collected in the northern Gulf of California, fewer daily increments were deposited in each year of growth (Fig. 7). In addition, these increments became progressively shorter through ontogeny (Table 3). Thus, like many of the modeled profiles, the reduction in amplitude is a function of both variables.

The LWSw/RIW model most closely resembles the growth patterns of specimen IP1-A1R. Figure 11 shows a comparison of annual $\delta^{18} \mathrm{O}$ amplitudes between the LWSw/RIW model (Fig. 3G; Table 2) and IP1-A1R, in which the 1993 and 1995 annual $\delta^{18} \mathrm{O}$ amplitudes from the IP1-A1R profile have been corrected to account for the influence of Colorado River water. In the first five years, the LWSw/RIW model has larger annual $\delta^{18} \mathrm{O}$ amplitudes. This likely reflects longer growth periods in the modeled profile than in the actual bivalve. The first four years in the modeled profile have growth periods of $365,334,237$, 
and 214 days (see Table 2). In contrast, the first four full years of growth in IP1-A1R have growth periods of 329, 243,184 , and 124 days (see Table 3 ). In the sixth year of the comparison, IP1-A1R has a larger annual amplitude than the LWSw/RIW model (Fig. 11). This suggests that the actual bivalve grows for a longer portion of the years than the modeled profile. Alternatively, the actual bivalve could have had the same growth period as the modeled profile, but deposited shell during an interval with a large change in ambient conditions. Regardless, the comparison in Figure 11 suggests that this modeled profile closely reflects the patterns of $\delta^{18} \mathrm{O}$ variation in actual bivalves from the northern Gulf of California.

\section{Reconstructing the Fullest Range of Recorded Environmental Conditions}

When bivalves do not grow, no environmental record is preserved. In the bivalve collected from the northern Gulf of California, fewer daily increments were deposited in each successive year, and the duration of growth halts increased. There is no geochemical record of the conditions that the bivalve experienced during these hiatuses. Thus, a smaller proportion of environmental conditions is recorded each year, and annual isotopic amplitudes decrease.

Part of the amplitude reduction, however, results from reduced sample resolution. That is, environmental conditions experienced during growth are recorded, but within smaller daily increments. Because increments narrow each year, more time is represented in samples from later ontogenetic stages. For example, in the bivalve's first year (1990), the widest increments are approximately $350 \mathrm{mi}$ crons (Fig. 7; Table 3). Thus, samples from this part of the shell can represent less than a single day of growth. In contrast, the widest increments in the third year of growth (1992) are approximately 150 microns, and a 300-micron sample might represent two days of growth. Thus, as increment widths decrease through ontogeny, sample resolution also decreases. $\delta^{18} \mathrm{O}$ values from these samples represent time-averaged conditions, which can obscure extreme values over the sampled interval.

The effects of this type of time-averaging are most pronounced in samples from slow-growing parts of the shell. In $C$. cortezi the narrowest increments often are deposited in the late fall or early spring (Goodwin et al, 2001; Schöne et al., 2002), and $\delta^{18} \mathrm{O}$ samples from these slow-growing parts of the shell define winter peaks. Thus, narrowing of increment widths in the late fall and early spring, and the resulting time-averaging of $\delta^{18} \mathrm{O}$ samples, causes a reduction in the annual amplitude by producing less positive winter peaks.

Unlike the component of amplitude reduction that results from growth halts, during which the environmental conditions are not recorded, some amount of the amplitude reduction that results from coarser samples may be restored. Figure 6 shows the 1992/1993 and 1993/1994 winter peaks from the observed $\delta^{18} \mathrm{O}$ profile from the northern Gulf of California specimen. Two profiles are shown for each winter peak: 300-micron, low-resolution samples (filled circles), and 50-micron, high-resolution samples (open squares). In both years, the most positive $\delta^{18} \mathrm{O}$ value in the 50 -micron profile is more positive than in the 300-micron profile. This difference reflects the smaller number of daily increments in the 50-micron samples. Be- cause these samples are less time-averaged than the 300micron samples, they can record more extreme values. Thus, they provide better estimates of the full range of environmental conditions that the bivalve experienced while it was growing.

\section{IMPLICATIONS FOR PALEOENVIRONMENTAL RECONSTRUCTION}

The intra-annual growth pattern can affect the $\delta^{18} \mathrm{O}$ profile in two ways: (1) changes in the daily increment widths can alter the shape of the $\delta^{18} \mathrm{O}$ profile; and (2) changes in sample resolution associated with increment width variation can reduce annual isotopic amplitudes. Altering the shape of the profile is important because the patterns of environmental change (e.g., intra-annual temperature changes) may no longer be reflected in the shape of the geochemical profile. For example, the FY-C. cortezi-increment-width profile (Fig. 3A) has its summer minimum value closer to the end of the year. However, the temperature model was a symmetrical sinusoid. Thus, it would be incorrect to assume that the hottest time of the year occurred after the mid-point of the year.

Changes in sample resolution affect the amount of timeaveraging in $\delta^{18} \mathrm{O}$ samples. For example, samples from slow-growing parts of the shell will contain a larger number of daily increments than from faster-growing parts of the shell. Thus, samples from different times of the year may represent environmental conditions at different temporal scales (also see Goodwin et al., 2001). Furthermore, low-resolution samples are less likely to reflect extreme environmental conditions and will contribute to a reduction of isotopic amplitudes in later stages of ontogeny. Therefore, recognition of intra-annual patterns of growth is critical to understanding seasonal changes in environmental conditions.

Sampling finer intervals later in ontogeny can recover a fuller range of environmental conditions. Although this procedure cannot reconstruct the full range of environmental conditions when seasonal shutdowns occur, it could be employed to estimate the temperatures controlling growth cessations through the life of a bivalve.

Reduction of isotopic amplitudes occurs in all models that include an ontogenetic decrease in growth rate. Because decreases in ontogenetic growth rate are so common, reduction in isotopic amplitude likely will be seen in most bivalves. The best estimates of the fullest range of environmental conditions are likely to be derived from the earliest years in an individual's ontogeny. Thus, to obtain multiple estimates of the full range of annual environmental conditions we suggest sampling early years from many shells rather than many years from few shells. That is, isotopic variation in the first year of many shells will provide a better estimate of inter-annual variability than will many years from a single shell.

\section{CONCLUSIONS}

(1) Modeled $\delta^{18} \mathrm{O}$ profiles indicate that ontogenetic decreases in growth rate result in the attenuation of isotopic amplitudes through the life of a bivalve. The reduction in annual amplitude is a function of shorter growth periods, reduced increment widths, or both. 
(2) In the modeled $\delta^{18} \mathrm{O}$ profiles presented here, shorter growth periods are more important than reduced increment widths in causing the ontogenetic amplitude reduction. However, the relative importance of these two factors likely reflects the choice of model parameters and may not represent universal patterns.

(3) Intra-annual variation in growth periods and rates affects the shape and sample resolution of $\delta^{18} \mathrm{O}$ profiles.

(4) Cuspate $\delta^{18} \mathrm{O}$ profiles with winter values less positive than expected and/or summer values more positive than expected can result from either variation in daily increment widths, cessations of growth, or both.

(5) Fine-resolution samples, with fewer daily increments than coarse-resolution samples, can be used to reconstruct a fuller range of recorded environmental conditions.

(6) Because daily increment widths decrease through ontogeny, finer resolution sampling strategies should be used for later years of growth.

(7) The best estimates of the fullest range of environmental conditions likely will be derived from the earliest years in an individual's ontogeny. To obtain multiple estimates of the full range of annual environmental conditions, we suggest sampling early years from many shells rather than many years from few shells.

\section{ACKNOWLEDGEMENTS}

We thank Karl W. Flessa for thoughtful discussions and suggestions. We also thank Ethan Grossman and an anonymous reviewer whose comments and criticisms improved an earlier version of the manuscript. DHG is indebted to Cary P. O'Brian for proof reading an earlier draft. This is CEAM publication 44.

\section{REFERENCES}

APPLEYARD, C.L., and DEALTERIS, J.T., 2001, Modeling growth of the northern quahog, Mercenaria mercenaria: Journal of Shellfish Research, v. 20, p. 1117-1125.

BERRY, W.B.N., and BARKER, R.M., 1975, Growth increments in fossil and modern bivalves: in Rosenberg, G.D., and Runcorn, S.K., eds., Growth Rhythms and the History of the Earth's Rotation: John Wiley \& Sons, New York, p. 9-25.

CoE, W.R., 1948, Nutrition, environmental conditions, and growth of marine bivalve mollusks: Journal of Marine Research, v. 7, p. 586-601.

DetTMAN, D.L., and LoHMANN, K.C., 1995, Microsampling carbonates for stable isotope and minor element analysis: Physical separation of samples on a 20 micrometer scale: Journal of Sedimentary Research, v. A65, p. 566-569.

Goodwin, D.H., Flessa, K.W., Schöne, B.R., and Dettman, D.L., 2001, Cross-calibration of daily increments, stable isotope variation, and temperature in the Gulf of California bivalve mollusk Chione cortezi: Implications for paleoenvironmental analysis: PALAIOS, v. 16, p. 387-398.

Grossman, E.L., and KU, T.L., 1986, Oxygen and carbon fractionation in biogenic aragonite: Temperature effects: Chemical Geology, v. 59, p. 59-74.
Hall, JR., C.R., Dollase, W.A., and Corbató, C.W., 1974, Shell growth in Tivela stultorum (Mawe, 1823) and Callista chione (Linnaeus, 1758)(Bivalvia): Annual periodicity, latitudinal differences, and diminution with age: Palaeogeography, Palaeoclimatology, Palaeoecology, v. 15, p. 33-61.

Hastings, J.R., 1964, Climatological data for Baja California: Technical Reports on the Meteorology and Climatology of Arid Regions, no. 14 , p. 93.

JONES, D.S., 1983, Sclerochronology; reading the record of the molluscan shell: American Scientist, v. 71, p. 384-391.

JonES, D.S., ARTHUR, M.A., and AlLARD, D.J., 1989, Sclerochronological records of temperature and growth from shells of Mercenaria mercenaria from Narragansett Bay, Rhode Island: Marine Biology, v. 102, p. 225-234.

JoNES, D.S., and QUITMYER, I.R., 1996, Marking time with bivalve shells: Oxygen isotopes and season of annual increment formation: PALAIOS, v. 11, p. 340-346.

Jones, D.S., Thompson, I., and AmBrose, W., 1978, Age and growth rate determinations for the Atlantic surf bivalve Spisula solidissima (Bivalvia: Mactracea), based on internal growth lines in shell cross-sections: Marine Biology, v. 47, p. 63-70.

JonES, D.S., WiLliams, D.F., and ARTHUR, M.A., 1983, Growth history and ecology of the Atlantic surf bivalve, Spisula solidisima (Dillwyn), as revealed by stable isotopes and annual shell increments: Journal of Experimental Marine Biology and Ecology, v. 73 , p. $225-242$.

KENNISH, J.M., and OLSSON, R.K., 1975, Effects of thermal discharge on the microstructural growth of Mercenaria mercenaria: Environmental Geology, v. 1, p. 41-64.

KING, M., 1995, Fisheries Biology, Assessment and Management: Fishing News Books, Oxford, 341 p.

KoIKE, H., 1980, Seasonal dating by growth-line counting of the bivalve, Meretrix lusoria: University of Tokyo Bulletin, v. 18, p. 1-120.

LUTZ, R.A., and RHOADS, D.C., 1980, Growth patterns within the molluscan shell: An overview: in Rhoads, D.C., and Lutz, R.A., eds., Skeletal Growth of Aquatic Organisms: Plenum Press, New York, p. 203-254.

OHNO, T., 1989, Palaeotidal characteristics determined by microgrowth patterns in bivalves: Palaeontology, v. 32, p. 237-263.

PanNella, G., and MacClintock, C., 1968, Biological and environmental rhythms reflected in molluscan shell growth: in Macurda, D.B., Jr., Paleobiological Aspects of Growth and Development, A Symposium: Paleontology Society Memoir, v. 42, p. 64-81.

SATO, S., 1995, Spawning periodicity and shell microgrowth patterns of the venerid bivalve Phacosoma japonicum (Reeve, 1850): Veliger, v. 38, p. 61-72.

SCHÖNE, B.R., and BENTLEY, D., 2002, Use of HMDS (hexamethyldisilazane) to dry organic microstructures in etched bivalve mollusk and barnacle shells: Nautilus, v. 116, p. 25-31.

Schöne, B.R., Goodwin, D.H., Flessa, K.W., Dettman, D.L., and ROOPNARINE, P.D., 2002, Sclerochronology and growth of the bivalve mollusks Chione fluctifraga and Chione cortezi in the northern Gulf of California, Mexico: Veliger, v. 45, p. 45-54.

WEFER, G., and BERGER, W.H., 1991, Isotope paleontology: Growth and composition of extant calcareous species: Marine Geology, v. 100 , p. 207-248.

Weidman, C.R., Jones, G.A., and Lohmann, K.C., 1994, The longlived mollusc Artica islandica: A new paleoceanographic tool for the reconstruction of bottom temperatures for the continental shelves of the northern North Atlantic Ocean: Journal of Geophysical Research, v. 99, p. 18305-18314.

ACCEPTED OCT. 15, 2002
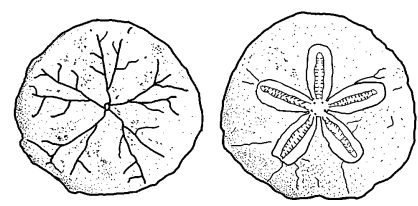